
\title{
$\begin{array}{ll}\text { Research Square } & \begin{array}{l}\text { Preprints are preliminary reports that have not undergone peer review. } \\ \text { They should not be considered conclusive, used to inform clinical practice, } \\ \text { or referenced by the media as validated information. }\end{array}\end{array}$
}

\section{BMP2 Signaling Activation Enhances Bone Metastases of None-small-cell Lung Cancer}

Fei Huang ( $\square$ feifeigood2148@126.com )

First Affiliated Hospital of Fujian Medical University https://orcid.org/0000-0001-9769-4798

\section{Yaqiang Cao}

University of the Chinese Academy of Sciences

\section{Gui Wu}

First Affiliated Hospital of Fujian Medical University

Junying Chen

First Affiliated Hospital of Fujian Medical University

Wanzun Lin

First Affiliated Hospital of Fujian Medical University

\section{Ruilong Lan}

First Affiliated Hospital of Fujian Medical University

\section{Bing Wu}

First Affiliated Hospital of Fujian Medical University

\section{Xianhe Xie}

First Affiliated Hospital of Fujian Medical University

Jinsheng Hong

First Affiliated Hospital of Fujian Medical University

\section{Lengxi Fu}

First Affiliated Hospital of Fujian Medical University

\section{Research}

Keywords: NSCLC, Bone metastases, BMP2 signaling, osteolytic mechanism, osteoblastic mechanism.

Posted Date: December 17th, 2019

DOl: https://doi.org/10.21203/rs.2.18934/v1

License: (c) (i) This work is licensed under a Creative Commons Attribution 4.0 International License. Read Full License 


\section{Abstract}

Background: Distant metastases occur when none-small-cell lung cancer (NSCLC) is at late stages. Bone metastasis is one of the most frequent metastases of NSCLC and leads to poor prognosis. It has been reported that high expression of BMP2 in NSCLC indicates poor survival, but whether BMP2 contributes to NSCLC bone metastasis remains largely unknown. Thus, we focus on the effects of BMP2 on NSCLC bone metastasis. Methods: Lewis lung carcinoma cells (LLCs) are injected into tail veins of C57/BL6 mice to establish lung and bone metastases models. The signaling pathway activation of LLC bone metastasis specimens are analyzed using RNA-seq. BMP signaling activation in LLC bone metastasis tissues are further conformed by immunofluorescence, immunohistochemistry and western blot. Moreover, BMP2 are used to treat NSCLC cells, and transwell assays are subsequently applied to examine the change in migration and invasion of NSCLC cells. Roles of BMP2 playing in osteolytic and osteoblastic mechanisms of NSCLC bone metastases are analyzed by Trap staining, ALP staining and Alizarin red staining. Results: In this study, activation of BMP signaling is found in bone metastasis tissues of mice lewis lung carcinoma and indicates poor survival in human NSCLC. Stroma fibroblasts can secret BMP2 to promote the migration and invasion of NSCLC cells. Besides, BMP2 signaling activation enhances the osteoclasts differentiation from macrophages to participate in osteolytic mechanism of NSCLC bone metastasis. Interestingly, NSCLC cells can also collect BMP2 from the microenvironment to further enhance the osteoblasts differentiation from pre-osteoblasts, which subsequently functions in osteoblastic mechanism. Conclusions: Our results indicate that BMP2 signaling activation enhances bone metastases of NSCLC not only through promoting migration and invasion of cancer cells, but also through both osteolytic and osteoblastic mechanisms. Thus, inhibition of BMP2 signaling can be a potential therapy choice for preventing bone metastases of NSCLC patients.

\section{Background}

Lung cancer is the leading cause of cancer death worldwide [1, 2]. Nearly $80 \%$ of lung cancer patients are None-small-cell lung cancer (NSCLC), with subtypes of adenocarcinoma and squamous cancer[3]. Distant metastasis frequently occurs when NSCLC is at late stages, which may result in poor prognosis. It has been reported that the median survival time of patients with NSCLC metastases is between 4-5 months, and one year survival rate is less than $10 \%[4]$. Following breast cancer and prostate cancer, NSCLC is the third most common cancer type that can lead to bone metastasis. About 30\%-40\% NSCLC patients are diagnosed with bone metastases at late stages [5]. Moreover, lung adenocarcinomas are more commonly seen among NSCLC patients with bone metastases compared with squamous cancers [6-10].

The high expression of bone morphogenic protein 2 (BMP2) has been reported in NSCLC[11]. The activation of BMP2 signaling is also found to enhance cell proliferation, tumorigenesis and lung metastases of lung adenocarcinoma[12,13]. In addition, the high expression of BMP2 in the stroma indicates poor prognosis in NSCLC[14]. However, the roles of BMP2 playing in NSCLC bone metastases still remain largely unknown and the detailed mechanisms are unclear. Usually, according to the effect of 
cancers on normal bone remodeling[15, 16], bone metastases can be further classified into osteolytic, osteoblastic or mixed subtypes.

Osteolytic, which is characterized by bone resorption induced by activated osteoclasts, frequently occurs in breast cancer, renal cell carcinoma, melanoma and thyroid cancer[9, 15-17]. Previous reports have also revealed that the osteolytic mechanism also presents in NSCLC $[10,18]$. Parathyroid hormone-related peptide (PTHrP) and NF-kappaB ligand (RANKL), which play significant roles in osteoclasts activation and bone metastases $[17,18]$, are found to be associated with NSCLC bone metastases[19, 20]. Moreover, miRNA-33a, targeting PTHrP, is confirmed to reduce bone resorption in NSCLC[20]. In addition, matrix metalloproteinase (MMPs), contributing to extracellular matrix degradation and interaction between cancer cells with stroma, have been reported to be involved in bone metastasis[5, 21, 22]. Thus, signaling pathways, like transforming growth factor (TGF- $\beta$ ), BMPs, Wnt, CXCR4 and NFkB, which can activate MMPs, may also contribute to NSCLC bone metastases via MMPs[8, 18].

The osteoblastic mechanism is usually found in prostate cancer[23]. Osteogenesis associated factors, such as TGF- $\beta$, BMPs and endothelin-1, play important roles in immature bones formation within tumors[17, 24, 25]. However, different from osteolytic, the detailed osteoblastic mechanism in bone metastases remains largely unknown. Although the preliminary osteolytic mechanism of NSCLC bone metastases has been revealed, it's still unclear about whether the osteoblastic mechanism also occurs in NSCLC bone metastases.

Here we investigate how BMP2 signaling activation functions in bone metastases of NSCLC. In this study, BMP signaling is found to be activated in bone metastasis tissues of mice lewis lung carcinoma and indicates poor survival in human NSCLC. BMP2, derived from the stroma fibroblasts, promotes the migration and invasion of NSCLC cells. Besides, BMP2 signaling activation can enhance the osteoclasts differentiation from macrophages to participate in osteolytic mechanism of NSCLC bone metastasis. What's more, NSCLC cells can also collect BMP2 from the microenvironment into vesicles to attach to preosteoblasts to enhance its osteoblasts differentiation, which subsequently functions in osteoblastic mechanism. Our results indicate that the function of BMP2 signaling in the bone metastases of NSCLC is a mixed mechanism. Taken together, inhibition of BMP2 signaling may be a new therapy choice for the NSCLC bone metastasis patients.

\section{Materials And Methods}

Antibodies and reagents. Antibodies were used in this study: monoclonal anti-Smad1/5 (Cell Signaling Technology, 6944); anti-pSmad1/5 (Cell Signaling Technology, 9516); anti-Smad1 (Abcam, ab63356); anti-CK18 (MutiSciences, 70-ab36769-050); anti-p-Akt (Cell Signaling Technology, 4060); anti-Akt (Cell Signaling Technology, 2920); anti-p-Erk (Cell Signaling Technology, 4370); anti-Erk (Cell Signaling Technology, 4695); anti-Ki67-FITC (Biolegend, 652409); TRITC-conjugated anti-Rabbit antibody (abclonal, AS040); FITC-conjugated anti-Mouse antibody (abclonal, AS001) and anti- $\beta$-Actin (Sigma, A1978). 
Reagents: BMP2 (R\&D, 355-BM-100); DAPI (Solarbio, C0060) and CFSE (eBioscience, 65-0850-84). Tris$\mathrm{HCl}, \mathrm{NaCl}$ and other chemicals were from Sigma.

Cells. Lewis lung cells, NCIH-1373, A549 and MC3T3-E1 cells were from ATCC. The ATCC number of Lewis lung cells (LLCs) was CRL-1642. The ATCC number of NCIH-1373 cells was CRL-5866. The ATCC number of A549 cells was CCL-185. The ATCC number of MC3T3-E1 cells was CRL-2594. Lewis lung cells and $\mathrm{NCIH}-1373$ cells were cultured in RMPI1640 (Invitrogen, Carlsbad, CA, USA) with 10\% fetal bovine serum (FBS) (Hyclone, Utah, USA); A549 cells in DMEM (Invitrogen) with 10\% FBS (Hyclone) and MC3T3E1 cells in a-MEM (Invitrogen) with 10\% FBS (Hyclone).

Mice. C57/BL6 mice used in this study were bred and maintained in a specific pathogen-free animal facility at Fujian Medical University. Mice were euthanized with carbon dioxide asphyxiation. All animal experiments were approved by the Animal Ethical Committee of Fujian Medical University (2018-039).

Lewis lung carcinoma metastasis. $1 \times 10^{6}$ LLCs were injected into the tail veins of C57/BL6 mice to make the metastasis model. LLCs usually tend to transfer to the lungs and bones. 6-8 weeks after injection, mice were euthanized with carbon dioxide asphyxiation to get the metastasis tissues[26].

Hematoxylin and eosin stain. The tissues were embedded in paraffin to be cut into $2.5 \mu \mathrm{m}$ tissue sections. Tissue sections were dewaxed with xylene. Then sections were rehydrated with $100 \%-95 \%-75 \%$ alcohol gradients. Hematoxylin was stained for 20 minutes and then sections were differentiated with $1 \%$ hydrochloric acid for $30 \mathrm{~s}$. Then, after 15 minutes of PBS blue staining, eosin was stained for 3 minutes. After rinsing, sections were dehydrated with a gradient of $95-100 \%$ alcohol. Clear the sections with xylene for two times. Then sections were mounted with a neutral resin. Photos were taken by Olympus microscope BX53[26].

Immunohistochemistry. The tissues were embedded in paraffin to be cut into $2.5 \mu \mathrm{m}$ tissue sections. Tissue sections were dewaxed with xylene. Then sections were rehydrated with $100 \%-95 \%-75 \%$ alcohol gradients. After antigens were retrieved, the sections were incubated with the primary antibodies overnight at $4{ }^{\circ} \mathrm{C}$. Then the sections were incubated with secondary antibodies after briefly washed with PBS at room temperature for $2 \mathrm{~h}$. Finally, the sections were incubated with HRP-conjugated streptavidin for 10 minutes before diamino benzidine (DAB) $/ \mathrm{H}_{2} \mathrm{O}_{2}$ was used as the substrate for detection reaction. Photos were taken by Olympus microscope BX53[27].

Immunofluorescence. For tissue sections, the protocol was the same with immunohistochemistry before the primary antibodies incubated. For cells, cells were fixed with $4 \%$ Paraformaldehyde (Sigma) for 20 minutes. Then cells were permated with $0.5 \%$ Triton X-100 for five minutes at room temperature. $10 \%$ BSA was used to block the cells for 20 minutes at room temperature. After that, cells were incubated with primary antibodies overnight at $4{ }^{\circ} \mathrm{C}$. At the second day, cells and scetions were incubated with TRITC-or FITC-conjugated secondary antibody for one hour at room temperature. DAPI (Solarbio, C0060) was used to stain the nucleus. Images were taken by Zessis LSM 800 Laser scanning confocal microscope[28]. 
Immunoblotting. Cells and tissues were lysed with TNE buffer $(10 \mathrm{mM}$ Tris-HCl, $150 \mathrm{mM} \mathrm{NaCl}, 1 \mathrm{mM}$ EDTA, $0.5 \% \mathrm{NP} 40, \mathrm{pH}=7.5$ ). For immunoblotting assay, cell lysates were mixed with $4 \times$ loading buffer (40 mM Tris- $\mathrm{HCl}, 200 \mathrm{mM}$ DTT, 4\% SDS, 40\% Glycerol, 0.032\% Bromophenol Blue, $\mathrm{pH}=8.0$ ). The samples were run with $4 \%$ stacking gel and $10 \%$ separating gels. Then proteins on the gels were transferred to nitrocellulose filter membranes for antibodies incubated. The membranes' exposure was done with thermo Pierce ECL and FluorChem E (ProteinSimple)[29].

CFSE-labeled LLC cells. LLCs were resuspended in $1 \mathrm{~mL}$ PBS with 2.5uM CFSE. LLCs dyed in CFSE solution were vortex in $37^{\circ} \mathrm{C}$ water bath for 10 min. Cells were washed with complete RPMI- 1640 culture medium for twice before cultured[28].

Cell migration assays. $1 \times 10^{4}$ cells in free culture media were placed on the upper layer of Corning cell culture insert with $8.0 \mu \mathrm{m}$ polycarbonate membrane. The media with or without $20 \mathrm{ng} / \mathrm{mL}$ BMP2 were placed below the cell permeable membrane. Following an incubation period ( 24 hours) in $37{ }^{\circ} \mathrm{C}, 5 \% \mathrm{CO}_{2}$, the cells that had migrated through the membrane were stained with $0.1 \%$ crystal violet and counted[29].

Cell invasion assays. Corning cell culture insert with $8.0 \mu \mathrm{m}$ polycarbonate membrane were pre-treated with 10:1 DMEM and matrigels (BD BioSciences). $1 \times 10^{5}$ cells in free culture media were placed on the upper layer of the diluted matrigels. The media with or without $20 \mathrm{ng} / \mathrm{mL}$ BMP2 were placed below the cell permeable membrane. Following an incubation period (48 hours) in $37{ }^{\circ} \mathrm{C}, 5 \% \mathrm{CO}_{2}$, the cells that had migrated through the membrane were stained with $0.1 \%$ crystal violet and counted.

Cell proliferation and apoptosis assays. LLCs or MC3T3-E1 cells were placed on the upper layer of Corning cell culture insert with $3.0 \mu \mathrm{m}$ polycarbonate membrane. MC3T3-E1 cells were cultured in media with or without $200 \mathrm{ng} / \mathrm{mL} \mathrm{BMP2}$ for $24 \mathrm{~h}$. MC3T3-E1 cells were harvested to be stained with the Ki67FITC antibody or APC Annexin V Apoptosis Detection Kit with 7-AAD (Biolegend, 640930). Flow cytometric analysis was performed using BD FACS C6 Flow Cytometer. The results were analyzed by the software FlowJo 7.6.1.

ALP staining. LLCs or MC3T3-E1 cells were placed on the upper layer of Corning cell culture insert with $3.0 \mu \mathrm{m}$ polycarbonate membrane. MC3T3-E1 cells below were cultured in media with or without $200 \mathrm{ng} / \mathrm{mL}$ BMP2 to be differentiated for seven days. ALP staining was conducted with BCIP/NBT Alkaline Phosphatase Color Development Kit (Beyotime).

Alizarin red staining. LLCs or MC3T3-E1 cells were placed on the upper layer of Corning cell culture insert with $3.0 \mu \mathrm{m}$ polycarbonate membrane. MC3T3-E1 cells below were cultured in media with or without $200 \mathrm{ng} / \mathrm{mL}$ BMP2 to be differentiated for 14-21 days. After cells were fixed with 95\% Ethanol for five minutes, $1 \%$ Alizarin red $(\mathrm{pH}=8.3)$ was stained for 15 minutes.

Trap staining. Murine pre-osteoclast RAW 264.7 cells $\left(3 \times 10^{4}\right.$ cells/well) were seeded directly into the wells of the 6 -well co-culture plates, and murine pre-osteoblast MC3T3-E1 cells $\left(3 \times 10^{4}\right.$ cells/well) were seeded into the Corning Cell Culture Inserts with $0.4 \mu \mathrm{m}$ polycarbonate membrane of the co-culture 6-well 
plates. After MC3T3-E1 cells were attached to the membrane of the inserts, lung cancer cells $\left(3 \times 10^{4}\right.$ cells/well) were added on top of MC3T3-E1 cell layer in triplicate and treated with $20 \mathrm{ng} / \mathrm{mL}$ BMP2 or vehicle. The co-culture assays were performed in DMEM medium supplemented with $10 \%$ FBS and changed every two days. TRAP staining was performed on day 6 using a leukocyte acid phosphatase kit (Sigma, 387A)[26]. TRAP+-multinucleated cells were scored as mature osteoclasts and quantified.

Elisa assay. Tumor tissues were homogenized in PBS to be samples. All samples originated from tumors were quantified to the concentration $10 \mathrm{mg} / \mathrm{mL}$ by BCA assay. The BCA kit was from Byeotime (P0009). Samples from tumors or supernatant form cell cultures were subjected to BMP2 elisa assay (R\&D, DBP200).

RNA-seq and bioinformatics analysis. RNA library preparation was performed as described in the QIAseq Stranded RNA Library Kits (QIAGEN). Total RNA was extracted from mice tissues. The mRNA was fragmented to an average insert size of $200-400 \mathrm{bp}$. The cleaved RNA fragments were copied into firststrand cDNA using reverse transcriptase (Thermo Fisher Scientific) and random primers. The first-strand cDNA was converted into double-stranded DNA in the presence of dUTP. These cDNA fragments were subjected to the addition of a single ' $A$ ' base and subsequent ligation of the adapter. The products were purified and enriched via PCR to generate the final library. After testing quality using Qubit2.0 Fluorometer and Agilent 2100 Bioanalyzer (Agilent Technologies), the libraries were sequenced on the lllumina HiSeq platform (Illumina Inc., San Diego, CA, USA). Raw sequences were mapped to mouse genome mm10 by STAR (v2.5.4b) [30] with key parameters setting of -readMatesLengthsIn Equal --outFilterMultimapNmax 20 -alignEndsType Local -al ignSJDBoverhangMin 10 -alignMatesGapMax 10000 -alignIntronMax 100000 -alignSJstitchMismatchNmax 5 - 155 -outFilterScoreMinOverLread 0.3 outFilterMatchNminOverLread 0.3. The expression level FPKM values were obtained from Cuffnorm in Cufflinks package (v2.2.1) [31], further, significant differential expressed genes (BM vs Parent, LM vs Parent and BM vs LM) were called by Cuffdiff in Cufflinks packages, requiring $p$-value $<=0.01$ and fold change $>=1$, all significant differential expressed genes were compiled together to show clusters in Fig. 3A. The find GO.pl implemented in HOMER [32] was used to test the enriched GO terms. Terms from KEGG pathways, $p$-value $<1^{e-5}$ and at least each 5 genes involved in a term were required for enriched terms. Expression profiles and clinical data of lung adenocarcinoma (LUAD) and lung squamouse cell carcinoma (LUSC) were downloaded from The Cancer Genome Atlas (TCGA) [33]. The survival analysis was carried based on mean expression for the gene list of different modules.

Statistical analysis. The student's t-test, one-way anova test, wilcox rank sum test, log-rank test were used. $P<0.05$ were considered statistically significant.

\section{Results}

BMP signaling signature was upregulated in lewis lung carcinoma bone metastases and indicated poor survival in NSCLC 
Lewis lung carcinoma originated from a spontaneous lung adenocarcinoma of a C57/BL6 mouse[28, 29]. We injected the lewis lung carcinoma cells (LLCs) into tail veins of C57/BL6 mice, resulting in lung metastases and bone metastases. RNA-seq was carried for bone metastasis tissues, lung metastasis tissues and parental lewis lung cells to analyze the transcriptome differences. The compiled significant differential expressing genes (DEGs) could be classified into five clusters C0, C1, C2, C3 and C4, indicating different expression patterns (Fig. 1A). The $\mathrm{C} 0$ module showed high expressing level in both metastasis tissues, meanwhile $\mathrm{C} 1$ and $\mathrm{C} 2$ showed higher expressing level in bone metastasis tissues than in lung metastasis tissues and parental cells, and the C3 and C4 module showed the unique highly expressed genes in lung metastasis tissues or parental cells (Fig. 1A). Thus, genes in C1 and C2 were more likely to contribute to lewis lung carcinoma bone metastasis. Consistently, ANGPT1 in C1, and MMPs and EDN1 in C2 had been reported to take part in prostate cancer bone metastasis [21, 34-36]. Significant KEGG pathways were enriched in C0, C2, and C4 modules, shown in Fig. 1B. Enriched KEGG pathways for different modules indicated that Jak-Stat signaling and PI3K-Akt might contribute to lung carcinoma metastasis while VEGF signaling, NF-KB signaling and HIF-1 a signaling was enriched in parental lewis lung tissues (Fig. 1B). ECM-receptor interaction and amoebiasis associated gene were upregulated in the $\mathrm{C} 2$ module, indicating that cell deformation and invasion might be significant in the formation of bone metastasis lesions (Fig. 1B). Furthermore, we analyzed the homologous gene expression features of human based on TCGA data (NSCLC subtypes: LUSC and LUAD) [33] and found that high expression of bone metastasis associated genes identified in cluster $\mathrm{C} 2$ indicated poor survival in human NSCLC (Fig. 1C). What's more, ANGPT1, MMPs and EDN1, the majorly upregulated genes in C2, were found as downstream targets of BMP signaling $[18,35,36]$. Thus, we came to the hypothesis that BMP signaling might contribute to lewis lung carcinoma bone metastasis. As TGF- $\beta$ signaling was important in bone metastasis of various types of cancer, like prostate cancer and breast cancer[37], we also analyze the activation of TGF- $\beta$ signaling in lewis lung carcinoma bone metastasis. To analyzed whether TGF- $\beta$ or BMP signaling was activated in bone metastasis tissues of lewis lung carcinoma, average expression of TGF- $\beta$ or BMP signaling targeted genes in LLCs were defined as TGF- $\beta$ or BMP signaling signatures to characterize the activation of TGF- $\beta$ or BMP signaling. Interestingly, we found that BMP signaling signature but not TGF- $\beta$ signaling signature was higher in bone metastasis tissues than in lung metastasis tissues and parental lewis lung cells (Fig. 1D). Besides, up regulation of BMP signaling signature genes also indicated poor survival in human NSCLC (Fig. 1F). Moreover, We conformed that human and mice NSCLC cell lines were respond to BMP signaling in vitro (Fig. 1E). We pre-treated LLCs with vehicle or $20 \mathrm{ng} / \mathrm{mL}$ BMP2 for $24 \mathrm{~h}$. After that, we injected the vehicle or $20 \mathrm{ng} / \mathrm{mL}$ BMP2 pre-treated LLCs into the tail veins of C57BL/ 6 mice. Furthermore, we find that lung and bone metastasis of BMP2 LLCs caused mice to start to die less than 20 days but mice injected with WT LLCs could survive for a long time (Fig. 1G). Taken together, activation of BMP signaling was found in lewis lung carcinoma bone metastases and indicated poor survival in NSCLC.

Expression of nuclear Smad1 indicated the activation of BMP signaling in bone metastasis tissues of lewis lung carcinoma. 
We found that LLCs could colonize to both limbs and spines to form bone metastasis lesions (Fig. 2A). When BMP signaling is activated, Smad1/5/8 is phosphorylated and translocated into nucleus with Smad4[38, 39]. In our results, we found that Smad1 was expressed in the nucleus of lewis lung carcinoma cells at the invasive sites, where bone resorption and destruction occurred (Fig. 2B-C). Those results suggested that BMP signaling was activated in bone metastasis tissues of lewis lung carcinoma. CK18, as a kind of cytokeratins, frequently expressed in NSCLC[31-33, 40]. We stained lewis lung carcinoma cells with CK18 and Smad1 to further confirm that BMP signaling was activated in lewis lung carcinoma cells rather than other cell types of bone metastasis tissues. As shown in Fig. 2C, nuclear Smad1 staining was usually found in $\mathrm{CK} 18^{+}$LLCs in bone metastasis tissues, indicating that BMP signaling is activated in lewis lung carcinoma cells when bone metastases occurred.

The activation of BMP signaling was higher in bone metastasis tissues than in lung metastasis tissues of lewis lung carcinoma.

Smad1/5/8 phosphorylation and nuclear localization indicates the activation of BMP signaling[39, 41]. Although Smad1 was expressed both in lung metastasis tissues and bone metastasis tissues, the location of Smad1 within the two metastasis tissues was different (Fig. 3A-B). Smad1 majorly located in the nucleus at the invasive boundaries in bone metastasis tissues, while it diffused in both the cytoplasm and nucleus of carcinoma cells in lung metastasis tissues (Fig. 3A-B). Moreover, we found that, in comparison with parental LLCs and lung metastasis tissues, bone metastasis tissues expressed higher phosphorylated Smad1/5 (Fig. 3C). Therefore, the activation of BMP signaling was higher in bone metastasis tissues than in lung metastasis tissues of lewis lung carcinoma. We pre-treated LLCs with $20 \mathrm{ng} / \mathrm{mL}$ BMP2 for $24 \mathrm{~h}$. After that, we injected the $20 \mathrm{ng} / \mathrm{mL}$ BMP2 pre-treated LLCs into the tail veins of C57BL/6 mice.What's more, as shown in Fig. 3D, we found that BMP2 could induce more bone metastasis than lung metastasis in vivo. Our results indicated that BMP2 may probably play a more important roles in bone metastasis than in lung metastasis of NSCLC.

BMP2 signaling enhanced migration and invasion of NSCLC cells.

According to our transcriptome results,ECM-receptor interaction and amoebiasis associated genes were upregulated in bone metastasis tissues, indicating that cell deformation, migration and invasion might paly significant roles in the formation of bone metastasis lesions(Fig. 1B). Therefore, we examined whether BMP2 signaling could enhance migration and invasion of NSCLC cells via the transwell assay. We found that BMP2 could enhance the migration of NSCLC cells, LLC, NCIH-1373 and A549 in vitro (Fig. 4A-C). What's more, the invasion ability of LLC and A549 was also promoted by BMP2 (Fig. 4D-E). We went further to investigated the roles of BMP signaling playing in the invasion of NSCLC cells in vivo. We pre-treated LLCs with vehicle or $20 \mathrm{ng} / \mathrm{mL}$ BMP2 for $24 \mathrm{~h}$. After that, we injected the vehicle or $20 \mathrm{ng} / \mathrm{mL}$ BMP2 pre-treated LLCs into the hind leg muscles of C57BL/ 6 mice to analyze the invasion of lewis lung carcinoma in the hind legs. To retain the BMP2 signaling activation in the hind leg muscles, we repetitively injected $3 \mu \mathrm{g} / \mathrm{kg}$ vehicle or BMP2 into the hind leg muscles per week for three weeks. In the vehicle group, we found that the carcinoma and the muscles or bones grew separately, indicating that 
lewis lung carcinoma did not invade into muscles and bones (Fig. 4F). Differently, in the BMP2 group, the muscles had been destructed and the carcinoma had invaded into the bones, indicating that BMP2 could enhance the migration and invasion of lewis lung carcinoma cells in vivo (Fig. 4F). The activation of BMP2 signaling was confirmed by nuclear Smad1 staining and the levels of phosphorylated Smad1/5 (Fig. 4G-H).

BMP2 derived from the stroma fibroblasts enhanced migration and invasion of NSCLC cells.

Rajski et al. has reported that high BMP2 derived from stroma cells indicates poor outcome in lung adenocarcinoma[14]. Moreover, stroma derived BMP2 is important in osteogenesis[42]. Tumor stroma fibroblast cells secret diverse cytokines to enhance cancer progression[43, 44]. Thus, we came to the hypothesis that stroma fibroblasts derived BMP2 could enhance the migration and invasion of NSCLC cells to promote metastasis. We found that MEF (mice embryonic fibroblast) can secret much more BMP2 than LLC and pre-osteoblast cell MC3T3-E1(Fig. 5A). Moreover, the conditional media of MEF could promote the migration of LLC (Fig. 5B-C). Those findings suggested that MEF might enhance migration of LLCs via secreted BMP2. Furthermore, in consistent with the migration phenomena, the conditional media of MEF could enhance the invasion of LLCs (Fig. 5D). In the bone metastasis tissues of lewis lung carcinoma, we also found higher BMP2 expression in a-Sma ${ }^{+}$activated fibroblasts than other cell types (Fig. 5E). The results above indicated that fibroblast cells might be an important source of BMP2. BMP2 originated from stroma fibroblasts contributed to the migration and invasion of lewis lung carcinoma cells.

BMP2 contributed to NSCLC bone metastases via both osteolytic and osteoblastic mechanisms In osteolytic metastases, the destruction of bone is mediated by osteoclasts rather than tumor cells[34, 45]. BMP2 has also been reported to stimulate the activation of osteoclasts to regulate the balance of bone remodeling[36]. Osteoblasts and NSCLC cells in tumor microenvironment can cooperate with each other to induce osteoclasts differentiation from macrophages[45]. Thus, we continued to examine whether BMP2 could contribute to this process. We co-cultured the macrophage cell line RAW264.7 with LLC and MC3T3-E1 or A549 and MC3T3-E1 cells to induce its differentiation for 7 days. We found that without BMP2 stimulation, few macrophages could differentiate into TRAP $^{+}$osteoclast cells (Fig Sup 1AB). However, BMP2 could strongly enhance the differentiation of macrophages to osteoclasts, indicating that BMP2 signaling contributed to osteolytic metastasis (Fig Sup 1A-B). The bi-directional interactions between tumor cells and osteoclasts lead to both osteolysis and tumor growth[34, 45].

However, in bone metastasis tissues of lewis lung carcinoma, we could find the immature bone tissues, indicating that osteoblastic mechanisms might also play roles in bone metastases of lewis lung carcinoma (Fig. 6A). Thanks to the strong osteogenesis inducing ability of BMP2, we co-cultured LLCs and pre-osteoblasts MC3T3-E1 with BMP2 to mimic the neoplastic osteogenesis in vivo. Interestingly, LLCs could secret microvesicles, which subsequently attached to MC3T3-E1 cells under BMP2 treatment (Fig. 6B). Moreover, we cultured LLCs in the Corning cell culture insert with $3.0 \mu \mathrm{m}$ polycarbonate 
membranes and found that the microvesichles could pass through the $3.0 \mu \mathrm{m}$ polycarbonate and attached to the MC3T3-E1 cells below, indicating that the diameter of the microvesichles was less than 3.0 $\mu \mathrm{m}$ (Fig. 6B). Furthermore, we examined the osteoblast differentiation of MC3T3-E1 cells. We found that BMP2 could induce ALP ${ }^{+}$differentiated MC3T3-E1 cells, while microvesicles from LLCs could further enhance this process. Our results indicated that microvesicles from LLCs induced by BMP2 could enhance the early osteoblasts differentiation of MC3T3-E1 (Fig. 6C-D). In our study, BMP2 was found to co-localize with the microvesicles from LLCs, indicating that LLCs could collect BMP2 from microenvironment into the microvesicles, further enriching BMP2 to MC3T3-E1 cells (Fig. 6E). Then we examined the proliferation and apoptosis of MC3T3-E1 cells. We found that LLCs could enhance the expression of the proliferation marker, Ki67, in MC3T3-E1 cells and attenuate MC3T3-E1 apoptosis in the absence of BMP2, which might be another mechanism supporting neoplastic osteogenesis (Fig Sup 2AB). However, the formation of calcium nodes, which indicated the mature osteocytes, was inhibited by LLCs (Fig. 6F-G). It has been reported that cancer cells rely on direct calcium influx from osteogenic cells to form bone metastasis lesions [46], indicating that calcium tended to participate in signaling transduction but not inducing osteogenesis in bone metastasis tissues. Those results above show how NSCLC cells, pre-osteoblasts and BMP2 interact with each other in the formation of immature bone tissues in bone metastases.

\section{Discussion}

NSCLC is the third most common bone metastasis carcinoma, following breast cancer and prostate cancer[6, 7]. However, different from breast cancer and prostate cancer, researches focusing on mechanisms of NSCLC bone metastases are few. Although PTHrP and RANKL have been reported to be associated with NSCLC bone metastasis, effects of treatment targeting RANKL on NSCLC bone metastases are extremely limited[47]. Therefore, new mechanisms about NSCLC bone metastases and new targets for NSCLC bone metastasis therapy need to be researched. In our present work, we find that BMP2 signaling is activated in bone metastasis tissues of lewis lung carcinoma. More importantly, BMP2, majorly derived from stroma fibroblasts in vivo, can promote the migration and invasion of NSCLC cells, osteoclasts differentiation from macrophage and osteoblast differentiation from pre-osteoblast. Those results indicated that the activation of BMP signaling enhances the bone metastases of NSCLC from both osteoblastic and osteolytic mechanism, which may be a new target for NSCLC bone metastasis therapy in the future to prevent metastatic dissemination of cancer cells. Particularly, in our results, carcinoma associated fibroblasts (CAFs) are significant in NSCLC bone metastases via secretion of BMP2, which might need more attention in the future.

Formation of bone metastasis lesions needs collaboration of lung cancer cells and the microenvironment[17, 34]. BMP2 signaling can enhance the migration and invasion of NSCLC cells, it can promote the differentiation of osteoclasts and osteoblasts as well. Therefore, BMP2 signaling can promote bone metastases of lung carcinoma from multiple directions (Fig. 6H). At the early stage, BMP2 enhances lung cancer cells to invade to the bone tissues. On one hand, BMP2 signaling regulates the 
interaction among lung cancer cells, and macrophages to promote the differentiation of osteoclasts, further enhancing osteolysis in bone metastases. On other hand, BMP2 signaling can also play roles in the differentiation of osteoblasts to induce the formation of bone tissue within the bone metastases. However, the osteoblasts cannot form mature bone tissues. It has been reported that cancer cells rely on direct calcium influx from osteogenic cells to form bone metastasis lesions [46], indicating that the roles of immature bone tissues induced by BMP2 signaling may be the source of cytokines or matrix for the metastasis lesions maintaining.

Although the skeleton is a permissive environment, its physical properties make it a harsh and unwelcomed environment for the colonization of carcinoma cells. Therefore, the osteoclastic bone resorption, which occurs in osteolysis mechanism, is significant in most bone metastases[48]. Osteoclasts, the only cells capable of bone resorption, derive from myeloid lineage, which is reported to be controlled by RANKL, PTHrP and Jagged $1[49,50]$. RANKL can be secreted by osteoblast lineages or stromal cells, and PTHrp can be derived from tumor cells[48, 50]. BMP2 has been reported to induce osteoblasts to secret RANKL[51, 52]. In our study, BMP2 is found to promote osteoclasts differentiation from macrophages in cooperation with pre-osteoblasts and NSCLC cells, indicating its roles in osteolysis mechanism of NSCLC bone metastases. Thus, BMP2 properly enhance osteoclast activation indirectly through inducing secretion of RANKL from osteoblasts.

Osteoblastic mechanism of bone metastasis remains much more unexplored than osteolysis mechanism. We firstly report the osteoblastic mechanism of NSCLC bone metastasis. In consistent with the osteoblastic mechanism of prostate cancer bone metastases, BMP2 signaling play significant roles in the formation of immature bone tissues within NSCLC bone metastasis tissues. Membrane associated microvesicles from stromal cells or other cells in the osteogenesis niche, are important carriers for BMP2 delivered to mesenchymal stem cells or pre-osteoblasts[53]. In prostate cancer bone metastasis, cancer cells release BMP2 via microvesicles to promote pre-osteoblasts differentiation[54]. Interestingly, according to our results, it's fibroblasts rather than NSCLC cells and osteoblasts that are the origination of BMP2. However, NSCLC can collect BMP2 from the microenvironment and then secret BMP2 to preosteoblast cells via microvesicles to enhance the differentiation of osteoblasts, which may be a new mechanism about how NSCLC cells interact with pre-osteoblast cells.

BMPs belong to TGF- $\beta$ superfamily, including BMP2, BMP4, BMP6, BMP7 and so on[55]. We find that BMP2 signaling not only enhanced migration and invasion of NSCLC cells, but also contributed to osteolysis and immature osteogenesis in bone metastases. Although, the roles of other BMP family members in lung cancer have also been reported. Different from BMP2, BMP6 has been reported to be a tumor suppressor in lung cancer, which may be epigenetically silenced in lung cancer[56]. The roles of BMP4 and BMP7 in lung cancer may be controversial. Some researches indicate that BMP4 and BMP7 enhance invasion and metastasis of lung cancer while others not, which may need to be further confirmed [57-60]. 
In the future, different inhibitors targeting BMP signaling factors can be developed for NSCLC bone metastasis therapy. As various kinase inhibitors have been developed, BMP type I receptors, ALK2/3/6, and BMP type II receptors, BMPRII, ActRII and ActRIIB, can be good targets[56]. Besides, BMP2 antagonisms or antibodies targeting BMP2 can also be tried in clinical NSCLC bone metastasis therapy. Furthermore, as fibroblasts are the origination of BMP2, drugs targeting CAFs might be another choice for NSCLC bone metastasis therapy.

\section{Conclusions}

BMP2 signaling is activated in bone metastases of NSCLC. Moreover, BMP2 signaling activation indicates poor survival in both mice and human NSCLC. Furthermore, BMP2 enhances bone metastases of NSCLC not only through promoting migration and invasion of cancer cells, but also through both osteolytic and osteoblastic mechanisms. Altogether, inhibition of BMP2 signaling can be a potential therapy choice for preventing bone metastases of NSCLC patients.

\section{Abbreviations}

NSCLC: None-small-cell lung cancer

BMP: Bone morphogenic protein

PTHrP : Parathyroid hormone-related peptid

RANKL : NF-kappaB ligand

MMPs : Matrix metalloproteinase

TGF- $\beta$ : Transforming growth factor

CXCR4: C-X-C motif chemokine receptor 4

Smad1/5: Mothers against decapentaplegic homolog 1/5

CK18: Cytokeratin 18

Akt: AKT serine/threonine kinase

Erk: Extracellular signal-regulated kinase

FITC: Fluoresceine isothiocyanate

TRITC: Tetramethyl rodamine iso thio cyanate

DAPI: 4',6-diamidino-2-phenylindole 
CFSE: :5-(and 6)-Carboxyfluorescein diacetate, succinimidyl ester

LLC: Lewis lung carcinoma

EDTA: Ethylene diamine tetraacetic acid

DTT: Dithiothreitol

SDS: Sodium lauryl sulfate

ALP: Alkaline phosphatase

ANGPT1: Angiopoietin 1

EDN1: Endothelia 1

KEGG: Kyoto Encyclopedia of Genes and Genomes

PI3K: Phosphatidylinositol-4,5-bisphosphate 3-kinase

VEGF: Vascular Endothelial Growth Factor

HIF-1a: Hypoxia inducible factor 1 subunit alpha

LUSC: Lung squamous cell carcinoma

LUAD: Lung Adenocarcinoma

ECM: Extracellular matrix

\section{Declarations}

Ethics approval and consent to participate: No data from human samples.

Consent for publication: The results shown here were in part based upon data generated by the TCGA Research Network: https://www.cancer.gov/tcga.

Availability of data and materials: The datasets analysed during the current study are available in the TCGA Research Network: https://www.cancer.gov/tcga.

Competing interests: The authors declare that they have no competing interests.

Founding: We thank the grants from National Natural Science Foundation for Young Scholars of China (81702913), Project for Distinguished Young Scholars in Fujian Province (2018B051).

Authors' contributions: Fei Huang: Conceptualization; Data curation; Formal analysis; Funding acquisition; Roles/Writing - original draft. Yaqiang Cao: Conceptualization; Data curation; Formal 
analysis; Writing - review \& editing. Gui Wu: Data curation; Formal analysis; Writing - review \& editing. Junying Chen: Data curation. Wanzun Lin: Data curation. Ruilong Lan: Investigation. Bing Wu: Investigation. Xianhe Xie: Investigation. Jinsheng Hong: Investigation. Lengxi Fu: Investigation. All authors read and approved the final manuscript.

Acknowledgement: We thank the support from Fujian Platform for Medical Research, First Affiliated Hospital, Fujian Medical University.

\section{References}

1. Hanahan D, Weinberg RA: Hallmarks of cancer: the next generation. Cel/ 2011, 144:646-674.

2. Vargas AJ, Harris CC: Biomarker development in the precision medicine era: lung cancer as a case study. Nat Rev Cancer 2016, 16:525-537.

3. Brambilla E, Travis WD, Colby TV, Corrin B, Shimosato Y: The new World Health Organization classification of lung tumours. Eur Respir J 2001, 18:1059-1068.

4. Sharma SV, Bell DW, Settleman J, Haber DA: Epidermal growth factor receptor mutations in lung cancer. Nat Rev Cancer 2007, 7:169-181.

5. McAllister SS, Weinberg RA: The tumour-induced systemic environment as a critical regulator of cancer progression and metastasis. Nat Cell Bio/ 2014, 16:717-727.

6. Oliveira MB, Mello FC, Paschoal ME: The relationship between lung cancer histology and the clinicopathological characteristics of bone metastases. Lung Cancer 2016, 96:19-24.

7. Santini D, Barni S, Intagliata S, Falcone A, Ferrau F, Galetta D, Moscetti L, La Verde N, Ibrahim T, Petrelli F, et al: Natural History of Non-Small-Cell Lung Cancer with Bone Metastases. Sci Rep 2015, 5:18670.

8. Azad GK, Taylor B, Rubello D, Colletti PM, Goh V, Cook GJ: Molecular and Functional Imaging of Bone Metastases in Breast and Prostate Cancers: An Overview. Clin Nucl Med 2016, 41:e44-50.

9. Luftner D, Niepel D: Breast cancer and bone metastases: a call for appropriate treatment. Support Care Cancer 2016, 24:4075-4077.

10. Sathiakumar N, Delzell E, Yun H, Jooste R, Godby K, Falkson C, Yong M, Kilgore ML: Accuracy of Medicare Claim-based Algorithm to Detect Breast, Prostate, or Lung Cancer Bone Metastases. Med Care 2017, 55:e144-e149.

11. Langenfeld EM, Kong $Y$, Langenfeld J: Bone morphogenetic protein 2 stimulation of tumor growth involves the activation of Smad-1/5. Oncogene 2006, 25:685-692.

12. Hsu YL, Huang MS, Yang CJ, Hung JY, Wu LY, Kuo PL: Lung tumor-associated osteoblast-derived bone morphogenetic protein-2 increased epithelial-to-mesenchymal transition of cancer by Runx2/Snail signaling pathway. J Biol Chem 2011, 286:37335-37346.

13. Davis H, Raja E, Miyazono K, Tsubakihara Y, Moustakas A: Mechanisms of action of bone morphogenetic proteins in cancer. Cytokine Growth Factor Rev 2016, 27:81-92. 
14. Rajski M, Saaf A, Buess M: BMP2 response pattern in human lung fibroblasts predicts outcome in lung adenocarcinomas. BMC Med Genomics 2015, 8:16.

15. Quayle L, Ottewell PD, Holen I: Bone Metastasis: Molecular Mechanisms Implicated in Tumour Cell Dormancy in Breast and Prostate Cancer. Curr Cancer Drug Targets 2015, 15:469-480.

16. Selvaggi G, Scagliotti GV: Management of bone metastases in cancer: a review. Crit Rev Oncol Hematol 2005, 56:365-378.

17. Macedo F, Ladeira K, Pinho F, Saraiva N, Bonito N, Pinto L, Goncalves F: Bone Metastases: An Overview. Oncol Rev 2017, 11:321.

18. Popper HH: Progression and metastasis of lung cancer. Cancer Metastasis Rev 2016, 35:75-91.

19. Nakamura ES, Koizumi K, Kobayashi M, Saitoh Y, Arita Y, Nakayama T, Sakurai H, Yoshie O, Saiki I: RANKL-induced CCL22/macrophagederived chemokine produced from osteoclasts potentially promotes the bone metastasis of lung cancer expressing its receptor CCR4. Clin Exp Metastasis 2006, 23:9-18.

20. Kuo PL, Liao SH, Hung JY, Huang MS, Hsu YL: MicroRNA-33a functions as a bone metastasis suppressor in lung cancer by targeting parathyroid hormone related protein. Biochim Biophys Acta 2013, 1830:3756-3766.

21. Wood SL, Pernemalm M, Crosbie PA, Whetton AD: The role of the tumor-microenvironment in lung cancer-metastasis and its relationship to potential therapeutic targets. Cancer Treat Rev 2014, 40:558-566.

22. Massague J, Obenauf AC: Metastatic colonization by circulating tumour cells. Nature 2016, 529:298306.

23. An H, Tao N, Li J, Guan Y, Wang W, Wang Y, Wang F: Detection of Prostate Cancer Metastasis by Whole Body Magnetic Resonance Imaging Combined with Bone Scintigraphy and PSA Levels. Cell Physiol Biochem 2016, 40:1052-1062.

24. Keller ET, Zhang J, Cooper CR, Smith PC, McCauley LK, Pienta KJ, Taichman RS: Prostate carcinoma skeletal metastases: cross-talk between tumor and bone. Cancer Metastasis Rev 2001, 20:333-349.

25. Feeley BT, Gamradt SC, Hsu WK, Liu N, Krenek L, Robbins P, Huard J, Lieberman JR: Influence of BMPs on the formation of osteoblastic lesions in metastatic prostate cancer. J Bone Miner Res 2005, 20:2189-2199.

26. Huang F, Chen J, Wang Z, Lan R, Fu L, Zhang L: delta-Catenin promotes tumorigenesis and metastasis of lung adenocarcinoma. Oncol Rep 2018, 39:809-817.

27. Huang F, Shi Q, Li Y, Xu L, Xu C, Chen F, Wang H, Liao H, Chang Z, Liu F, et al: HER2/EGFR-AKT Signaling Switches TGFbeta from Inhibiting Cell Proliferation to Promoting Cell Migration in Breast Cancer. Cancer Res 2018, 78:6073-6085.

28. Huang F, Chen J, Lan R, Wang Z, Chen R, Lin J, Zhang L, Fu L: delta-Catenin peptide vaccines repress hepatocellular carcinoma growth via CD8(+) T cell activation. Oncoimmunology 2018, 7:e1450713. 
29. Huang F, Chen J, Lan R, Wang Z, Chen R, Lin J, Fu L: Hypoxia induced delta-Catenin to enhance mice hepatocellular carcinoma progression via Wnt signaling. Exp Cell Res 2019, 374:94-103.

30. Dobin A, Davis CA, Schlesinger F, Drenkow J, Zaleski C, Jha S, Batut P, Chaisson M, Gingeras TR: STAR: ultrafast universal RNA-seq aligner. Bioinformatics 2013, 29:15-21.

31. Trapnell C, Roberts A, Goff L, Pertea G, Kim D, Kelley DR, Pimentel H, Salzberg SL, Rinn JL, Pachter L: Differential gene and transcript expression analysis of RNA-seq experiments with TopHat and Cufflinks. Nat Protoc 2012, 7:562-578.

32. Heinz S, Benner C, Spann N, Bertolino E, Lin YC, Laslo P, Cheng JX, Murre C, Singh H, Glass CK: Simple combinations of lineage-determining transcription factors prime cis-regulatory elements required for macrophage and B cell identities. Mol Cell 2010, 38:576-589.

33. Cancer Genome Atlas Research N, Weinstein JN, Collisson EA, Mills GB, Shaw KR, Ozenberger BA, Ellrott K, Shmulevich I, Sander C, Stuart JM: The Cancer Genome Atlas Pan-Cancer analysis project. Nat Genet 2013, 45:1113-1120.

34. Labelle M, Begum S, Hynes RO: Direct signaling between platelets and cancer cells induces an epithelial-mesenchymal-like transition and promotes metastasis. Cancer Cell 2011, 20:576-590.

35. Larson SR, Zhang X, Dumpit R, Coleman I, Lakely B, Roudier M, Higano CS, True LD, Lange PH, Montgomery B, et al: Characterization of osteoblastic and osteolytic proteins in prostate cancer bone metastases. Prostate 2013, 73:932-940.

36. Colden M, Dar AA, Saini S, Dahiya PV, Shahryari V, Yamamura S, Tanaka Y, Stein G, Dahiya R, Majid S: MicroRNA-466 inhibits tumor growth and bone metastasis in prostate cancer by direct regulation of osteogenic transcription factor RUNX2. Cell Death Dis 2017, 8:e2572.

37. Juarez P, Guise TA: TGF-beta in cancer and bone: implications for treatment of bone metastases. Bone 2011, 48:23-29.

38. Miyazono K, Maeda S, Imamura T: BMP receptor signaling: transcriptional targets, regulation of signals, and signaling cross-talk. Cytokine Growth Factor Rev 2005, 16:251-263.

39. Wu M, Chen G, Li YP: TGF-beta and BMP signaling in osteoblast, skeletal development, and bone formation, homeostasis and disease. Bone Res 2016, 4:16009.

40. Bertram JS, Janik P: Establishment of a cloned line of Lewis Lung Carcinoma cells adapted to cell culture. Cancer Lett 1980, 11:63-73.

41. Sapkota G, Alarcon C, Spagnoli FM, Brivanlou AH, Massague J: Balancing BMP signaling through integrated inputs into the Smad1 linker. Mol Cell 2007, 25:441-454.

42. Fukunaga Y, Bandoh S, Fujita J, Yang Y, Ueda Y, Hojo S, Dohmoto K, Tojo Y, Takahara J, Ishida T: Expression of cytokeratin $\mathbf{8}$ in lung cancer cell lines and measurement of serum cytokeratin $\mathbf{8}$ in lung cancer patients. Lung Cancer 2002, 38:31-38.

43. Rasanen K, Vaheri A: Activation of fibroblasts in cancer stroma. Exp Cell Res 2010, 316:2713-2722.

44. Xouri G, Christian S: Origin and function of tumor stroma fibroblasts. Semin Cell Dev Biol 2010, 21:40-46. 
45. Mundy GR: Metastasis to bone: causes, consequences and therapeutic opportunities. Nat Rev Cancer 2002, 2:584-593.

46. Wei F, Zhou Y, Wang J, Liu C, Xiao Y: The Immunomodulatory Role of BMP-2 on Macrophages to Accelerate Osteogenesis. Tissue Eng Part A 2018, 24:584-594.

47. Ai-AqI ZS, Alagl AS, Graves DT, Gerstenfeld LC, Einhorn TA: Molecular mechanisms controlling bone formation during fracture healing and distraction osteogenesis. J Dent Res 2008, 87:107-118.

48. Croucher PI, McDonald MM, Martin TJ: Bone metastasis: the importance of the neighbourhood. Nat Rev Cancer 2016, 16:373-386.

49. Weidle UH, Birzele F, Kollmorgen G, Ruger R: Molecular Mechanisms of Bone Metastasis. Cancer Genomics Proteomics 2016, 13:1-12.

50. Esposito M, Guise T, Kang Y: The Biology of Bone Metastasis. Cold Spring Harb Perspect Med 2018, 8.

51. Mancino AT, Klimberg VS, Yamamoto M, Manolagas SC, Abe E: Breast cancer increases osteoclastogenesis by secreting M-CSF and upregulating RANKL in stromal cells. J Surg Res 2001, 100:18-24.

52. Ando T, Ichikawa J, Wako M, Hatsushika K, Watanabe Y, Sakuma M, Tasaka K, Ogawa H, Hamada Y, Yagita $\mathrm{H}$, Nakao A: TWEAK/Fn14 interaction regulates RANTES production, BMP-2-induced differentiation, and RANKL expression in mouse osteoblastic MC3T3-E1 cells. Arthritis Res Ther 2006, 8:R146.

53. Maredziak M, Marycz K, Lewandowski D, Siudzinska A, Smieszek A: Static magnetic field enhances synthesis and secretion of membrane-derived microvesicles (MVs) rich in VEGF and BMP-2 in equine adiposederived stromal cells (EqASCs)-a new approach in veterinary regenerative medicine. In Vitro Cell Dev Biol Anim 2015, 51:230-240.

54. Itoh T, Ito Y, Ohtsuki Y, Ando M, Tsukamasa Y, Yamada N, Naoe T, Akao Y: Microvesicles released from hormone-refractory prostate cancer cells facilitate mouse pre-osteoblast differentiation. $J \mathrm{Mol}$ Histol 2012, 43:509-515.

55. Guo X, Wang XF: Signaling cross-talk between TGF-beta/BMP and other pathways. Cell Res 2009, 19:71-88.

56. Huang F, Chen YG: Regulation of TGF-beta receptor activity. Cell Biosci 2012, 2:9.

57. Chen J, Ye L, Xie F, Yang Y, Zhang L, Jiang WG: Expression of bone morphogenetic protein 7 in lung cancer and its biological impact on lung cancer cells. Anticancer Res 2010, 30:1113-1120.

58. Huang Y, Xu Y, Bi Y, Xu M, Lu J, Wang T, Li M, Chen Y, Liu Y, Huang F, et al: Relationship between CA 19-9 levels and glucose regulation in a middle-aged and elderly Chinese population. J Diabetes 2012, 4:147-152.

59. Kim JS, Kurie JM, Ahn YH: BMP4 depletion by miR-200 inhibits tumorigenesis and metastasis of lung adenocarcinoma cells. Mol Cancer 2015, 14:173. 
60. Fang WT, Fan CC, Li SM, Jang TH, Lin HP, Shih NY, Chen CH, Wang TY, Huang SF, Lee AY, et al: Downregulation of a putative tumor suppressor BMP4 by SOX2 promotes growth of lung squamous cell carcinoma. Int J Cancer 2014, 135:809-819.

\section{Figures}

A

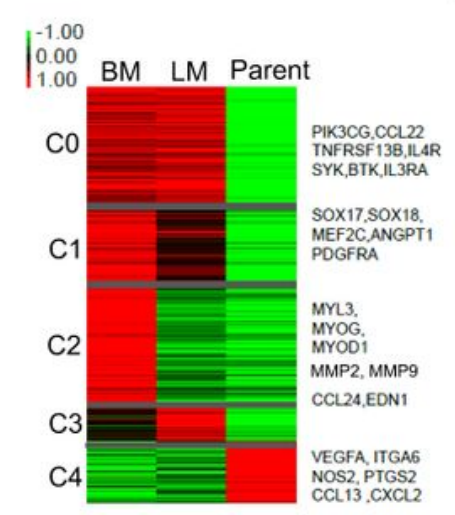

B

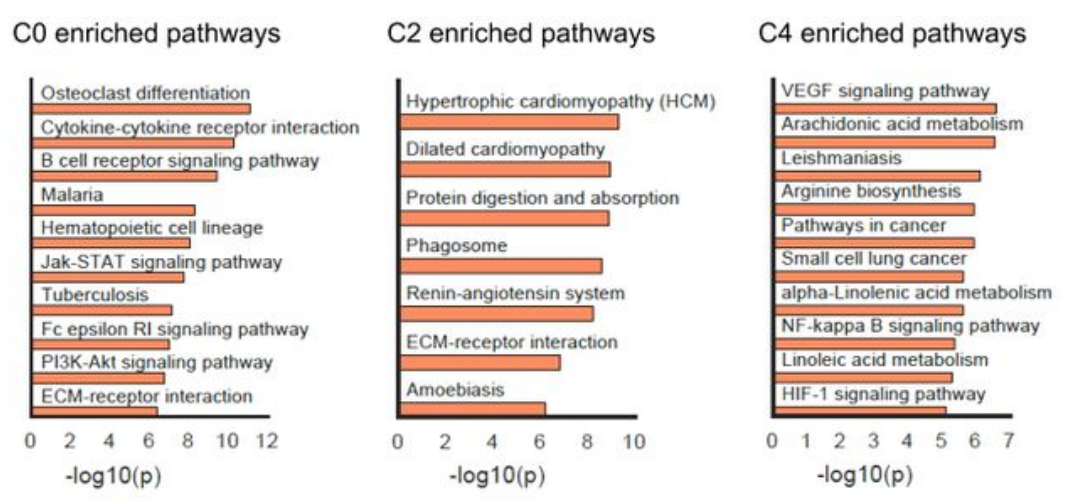

C
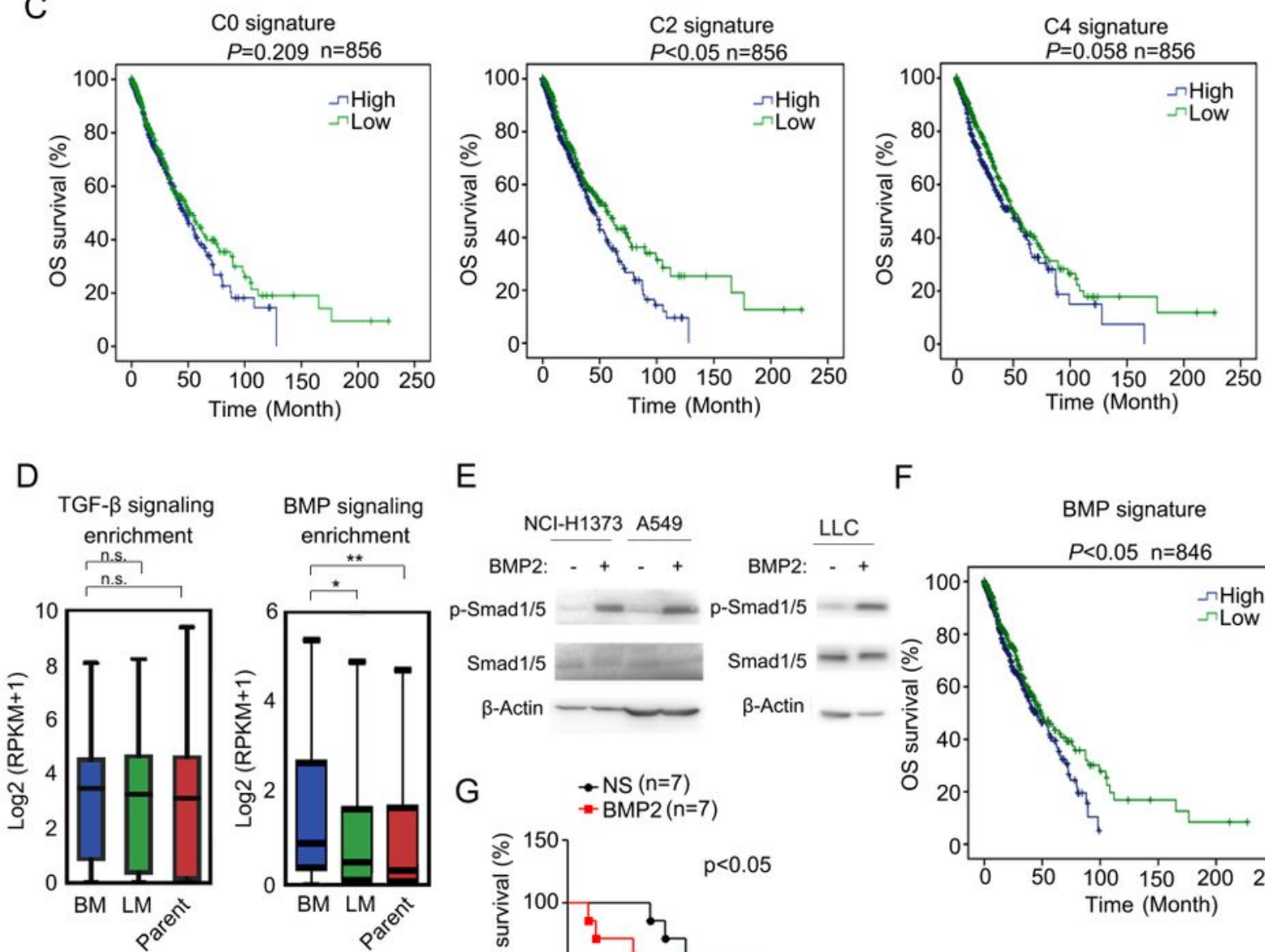

$E$

$\mathrm{F}$
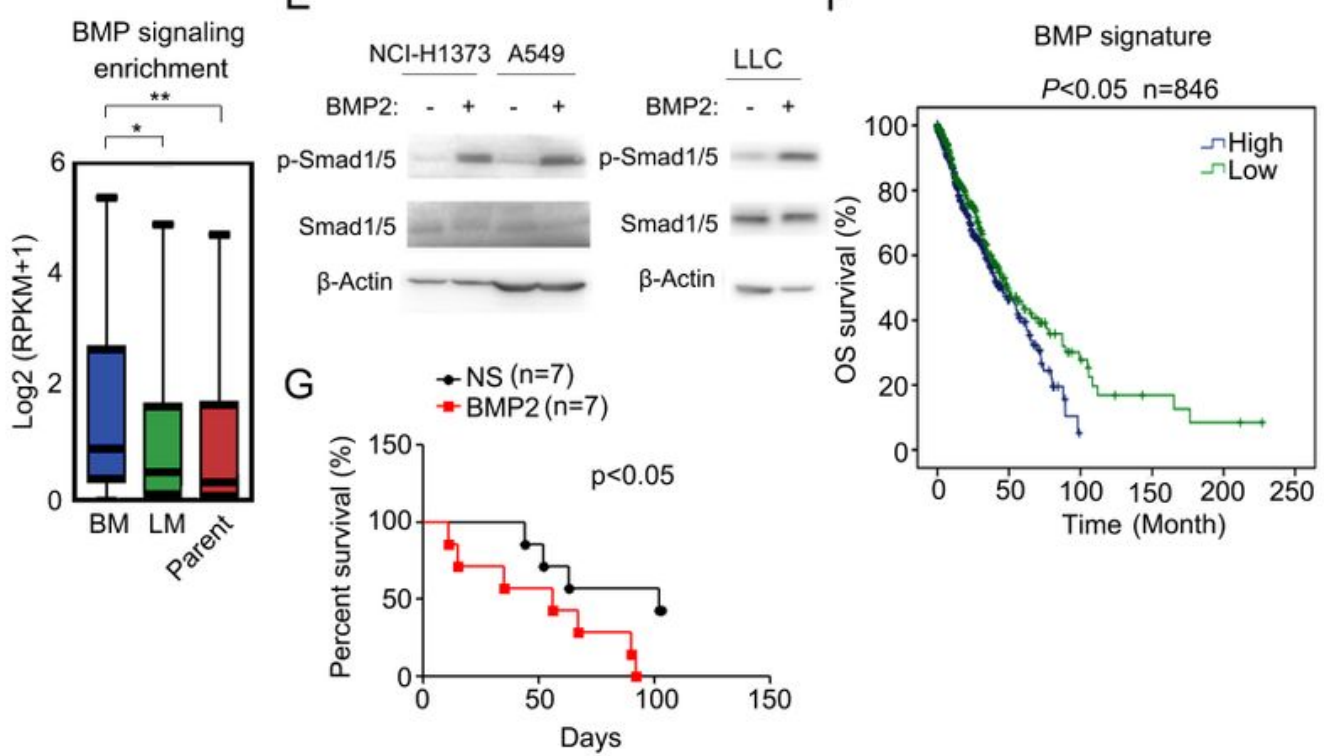
BMP signaling signature expression was up-regulated in LLC bone metastases and indicated poor survival. (A) Heatmap with expression characteristics of the five mRNA-based clusters in bone metastasis tissues, lung metastasis tissues and parental lewis lung cells. (B) The enriched KEGG pathways of C0, C2 and $\mathrm{C} 4$ clusters based on (A). (C) OS of TCGA patients with high $\mathrm{C} 0, \mathrm{C} 2$ or $\mathrm{C} 4$ signatures versus low $\mathrm{C}$, $\mathrm{C} 2$ or $\mathrm{C} 4$ signatures. The $\mathrm{p}$ value was based on the log rank test. $\left({ }^{*} \mathrm{P}<0.05,{ }^{\star *} \mathrm{P}<0.01\right)$ (D) TGF- $\beta$ and BMP signaling pathway expression in bone metastasis tissues, lung metastasis tissues and parental lewis lung cells. ( $\left.{ }^{*} \mathrm{P}<0.05,{ }^{*} \mathrm{P}<0.01\right)(\mathrm{E})$ Lysates of $\mathrm{NClH} 1373, \mathrm{~A} 549$ and $\mathrm{LLC}$ cells were indicated to immunoblotting. (F) OS of patients with high BMP signature versus low BMP signature. The p-value was based on the log rank test. $\left({ }^{\star} P<0.05,{ }^{\star *} P<0.01\right)(G) 1 \otimes 106$ LLC cells of different treatment were injected into the tail veins of $\mathrm{C} 57 \mathrm{BL} / 6$ mice. Death of mice were recorded and survival curves were drawn $\left({ }^{*} \mathrm{P}<0.05,{ }^{*} \mathrm{P}<0.01\right)$. 
A

B

C

$400 x$
Limbs
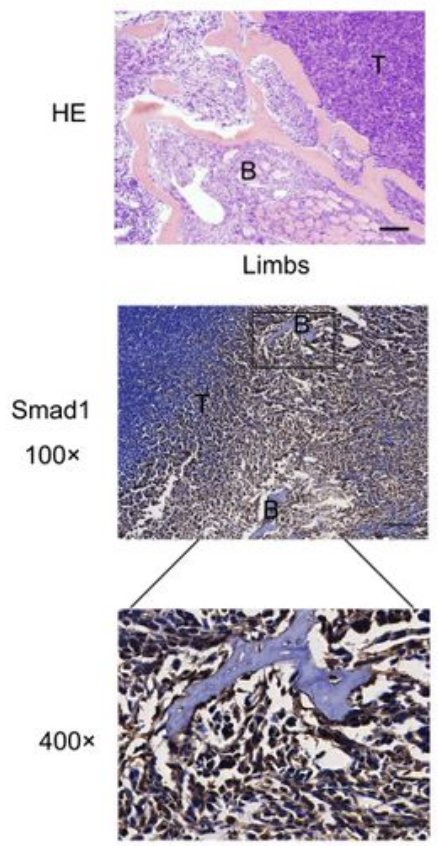

Limbs

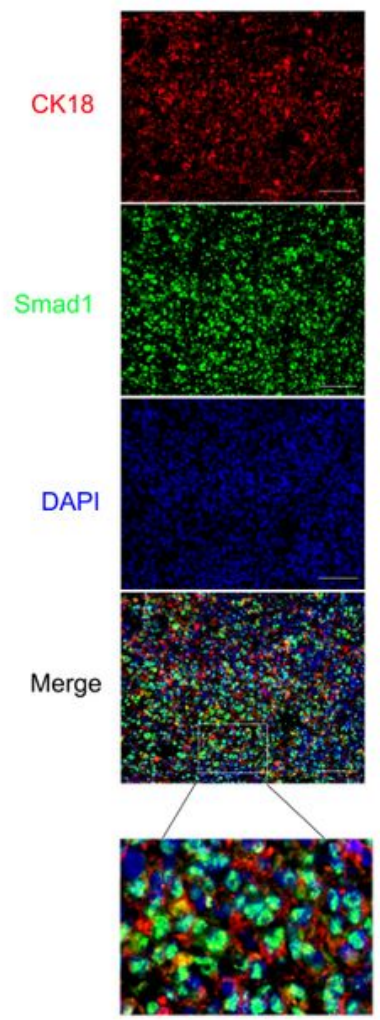

Limbs

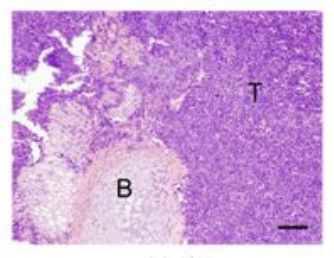

Limbs

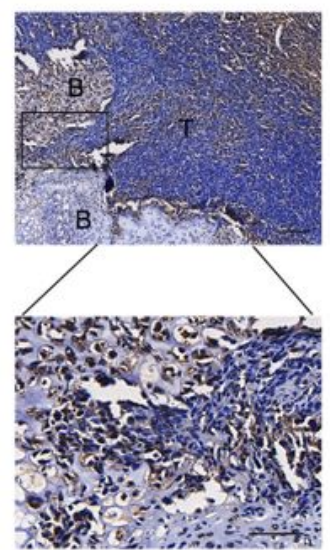

Limbs
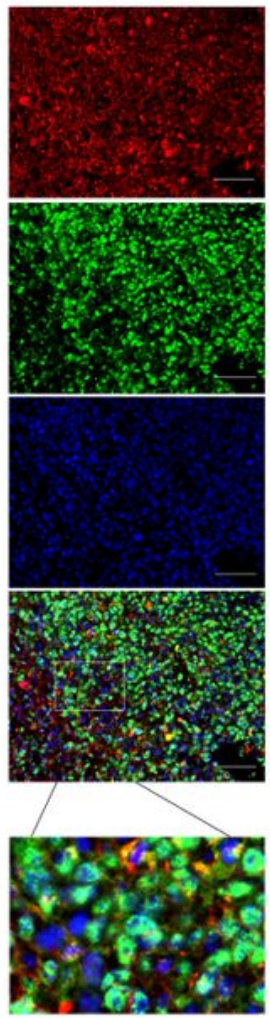

Spine

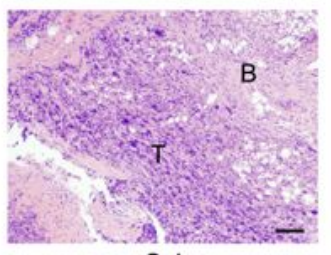

Spine

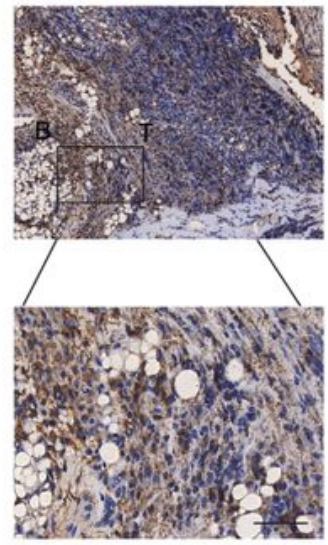

Spine
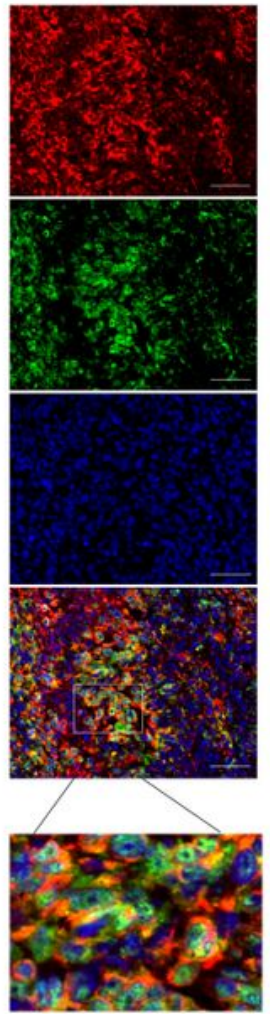

Figure 2

Nucelar Smad1 indicated the activation of BMP signaling in LLC bone metastasis tissues. (A) Lewis lung carcinoma cells (LLCs) were injected into tail veins of C57/BL6 mice, resulting in lung metastasis and bone metastasis. Representative histology analyses of bone metastasis tissues from limbs or spines

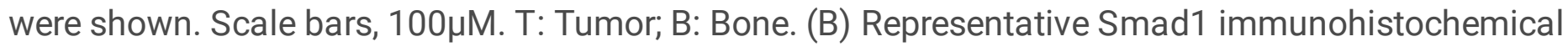
analyses of bone metastasis tissues from limbs or spines were shown. Scale bars of the 100x photos 
were $100 \mu \mathrm{M}$. Regions in the rectangles were magnified to $400 \times$. Scale bars of the $400 \times$ photos were $50 \mu \mathrm{M}$. T: Tumor; B: Bone. (C) Representative immunofluoresence photos of Smad1, CK18 and DAPI were shown. Scale bars of the $400 \times$ photos were $50 \mu \mathrm{M}$. Regions in the rectangles were magnified. Red: CK18TRITC; Green: Smad1-FITC; Blue: DAPI.
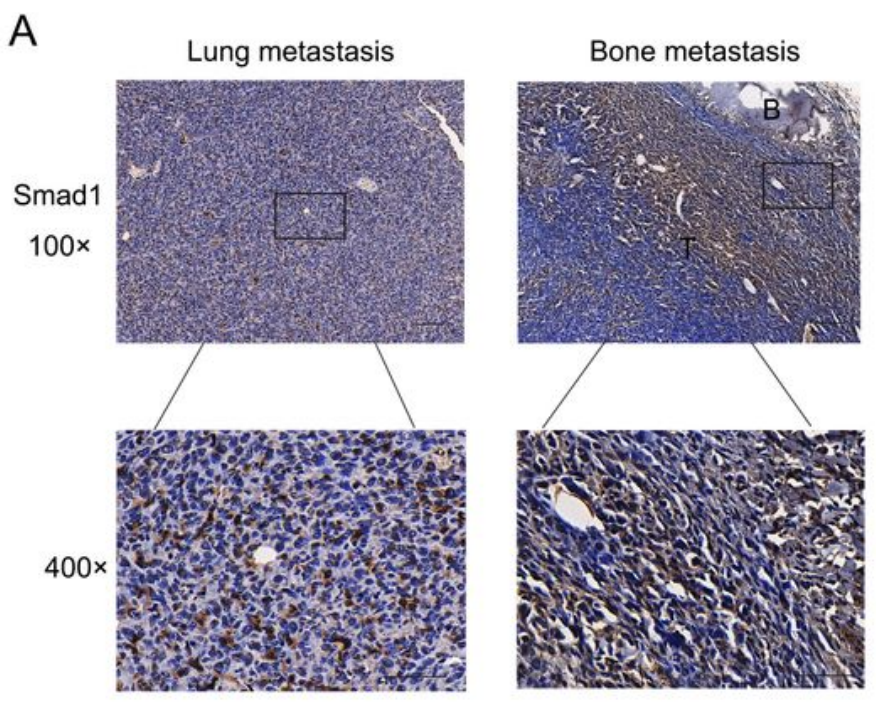

B
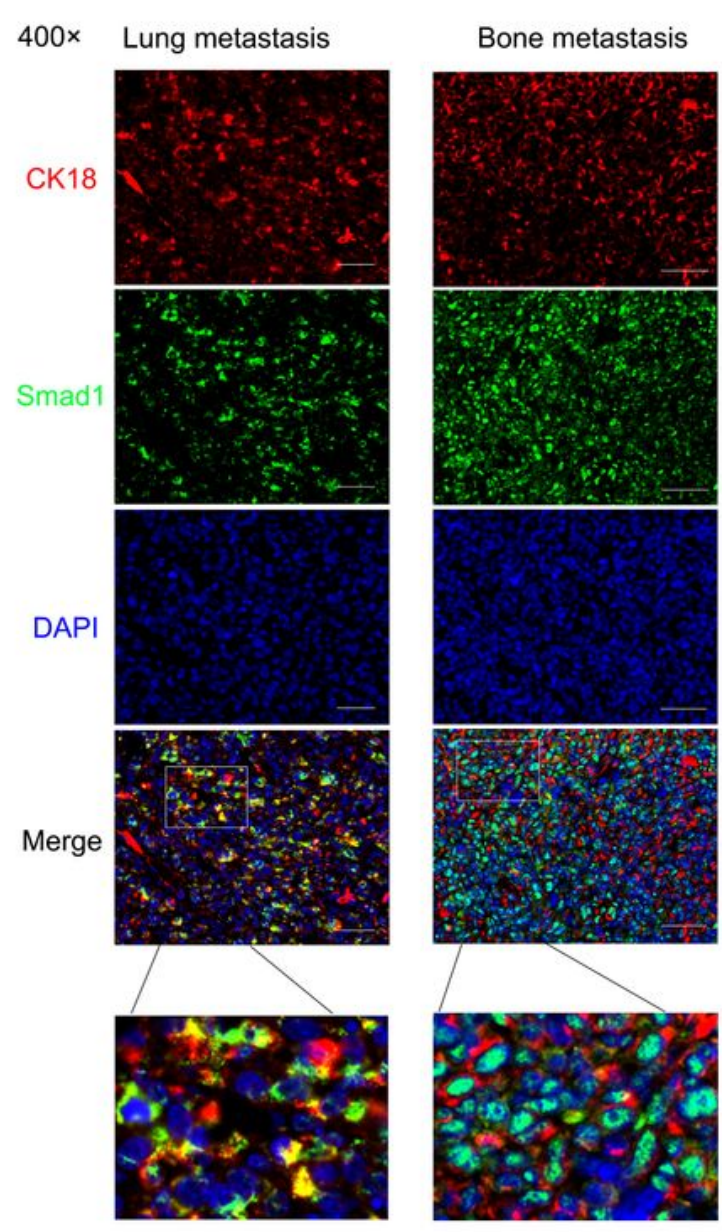

p-Smad1/5

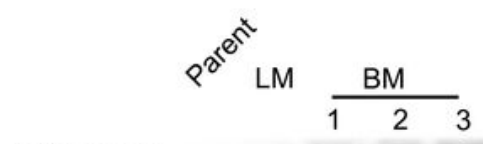

p-Smad1/5

Smad1/5

$\beta$-Actin

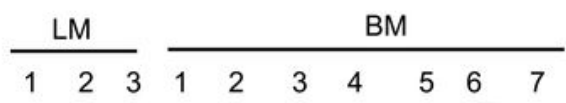

Smad1/5

$\beta$-Actin

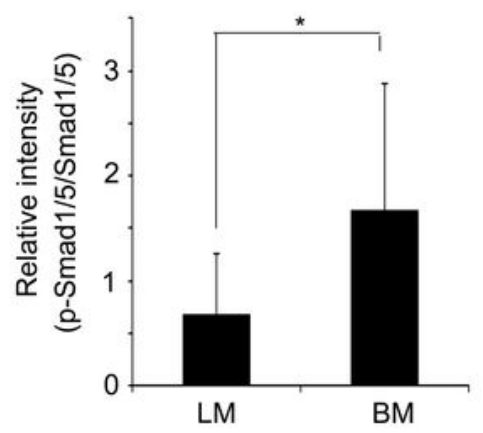

D

\begin{tabular}{ccc}
\hline Experimental number & 1 & 2 \\
\hline $\begin{array}{c}\text { Lung } \\
\text { metastasis/Total }\end{array}$ & $(1 / 6)$ & $(1 / 6)$ \\
Bone & & $(5 / 6)$ \\
metastasis/Total & $(3 / 6)$ & \\
\hline
\end{tabular}

Figure 3 
BMP signaling activation was higher in bone metastasis tissues than in lung metastasis tissues. (A) Representative Smad1 immunohistochemical analyses of lung or bone metastasis tissues were shown. Scale bars of the $100 \times$ photos were $100 \mu \mathrm{M}$. Regions in the rectangles were magnified to $400 \times$. Scale bars of the $400 \times$ photos were $50 \mu \mathrm{M}$. T: Tumor; B: Bone. (B) Representative immunofluoresence photos of

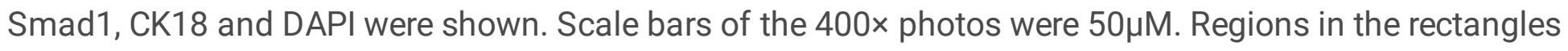
were magnified. The arrows indicated Smad1 in CK18+ cells. Red: CK18-TRITC; Green: Smad1-FITC; Blue: DAPI. (C) Lysates of LLC cells and lung or bone tissues were indicated to immunoblotting. The band intensity of was normalized to $\beta$-Actin. The ratio of $p$-Smad1/5 and Smad1/5 bands intensity was analyzed. The experiments were repeated for three times and the average relative band intensity was shown. $\left({ }^{*} P<0.05\right)$ (D) $1 \rrbracket 106$ LLC cells of BMP2 treatment were injected into the tail veins of $C 57 \mathrm{BL} / 6$ mice. Lung or bone metastasis of total mice were recorded.

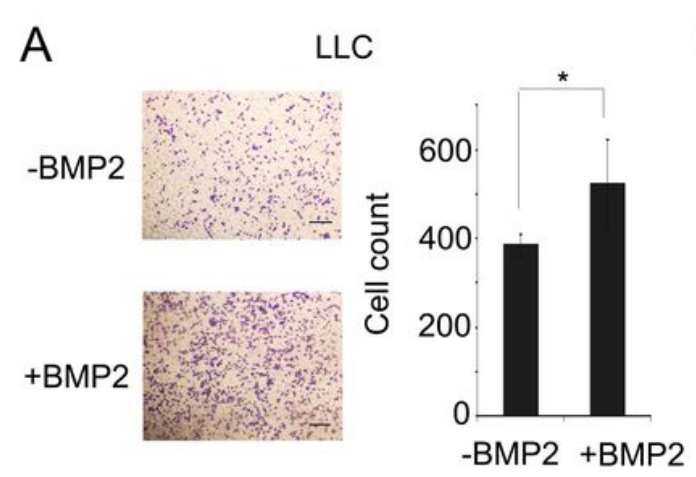

D

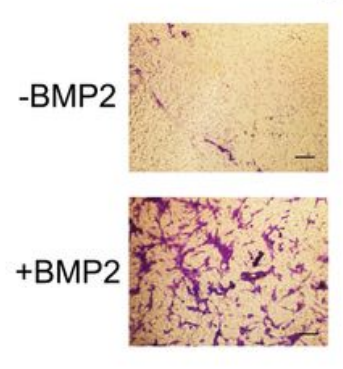

LLC

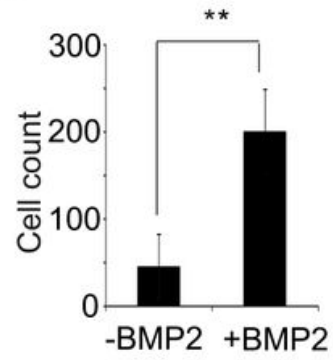

B

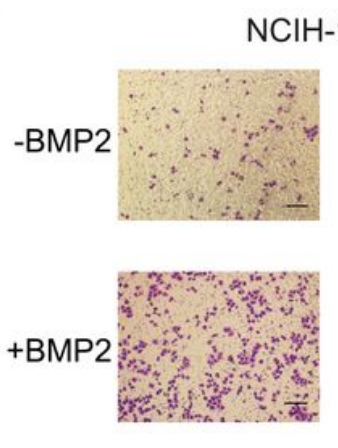

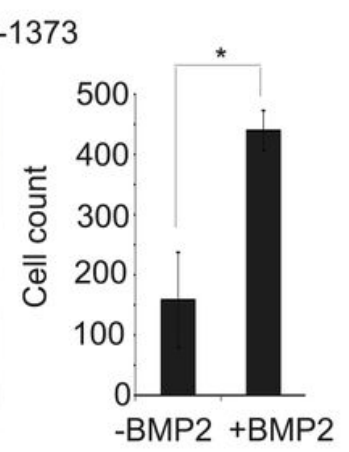

E
C

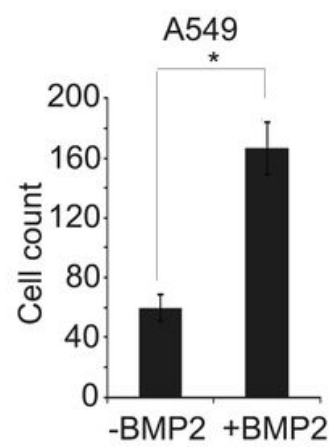

$\mathrm{F}$

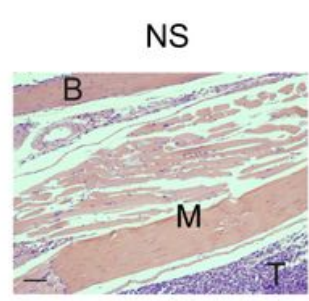

G

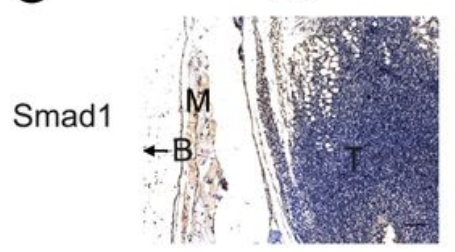

BMP2

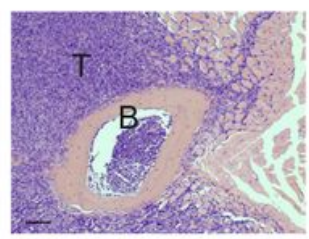

BMP2

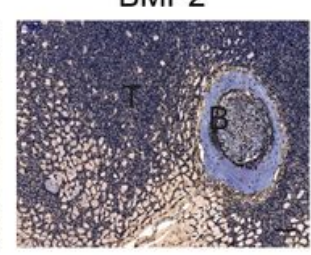

$\mathrm{H}$

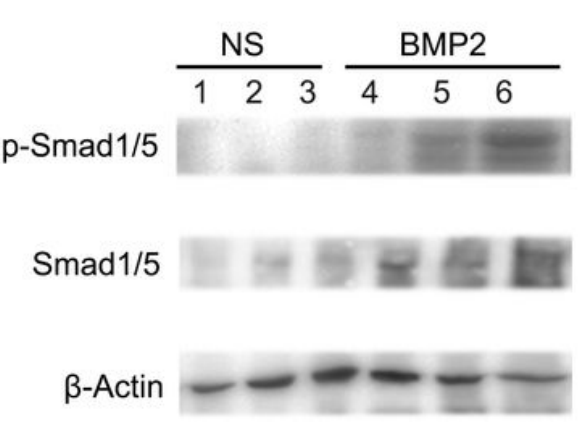


BMP2 signaling enhanced migration and invasion of NSCLC cells. $1 \times 104$ LLCs (A), NCIH-1373 cells (B) and A549 cells (C) in free culture media were placed on the upper layer of Corning cell culture insert with $8.0 \mu \mathrm{m}$ polycarbonate membrane. The media with or without $20 \mathrm{ng} / \mathrm{mL}$ BMP2 were placed below the cell permeable membrane. The cells migrating to the bottom were stained with crystal violet and counted. Representative photos were shown. Scale bars, $100 \mu \mathrm{M}$. Average cell numbers of at least three fields were shown on the right. ( $\left.{ }^{*} P<0.05,{ }^{*} \mathrm{P}<0.01\right)$ Corning cell culture insert with $8.0 \mu \mathrm{m}$ polycarbonate membrane were pre-treated with 10:1 DMEM and matrigels (BD BioSciences). 1×105 LLCs (D) and A549 cells (E) in free culture media were placed on the upper layer of the diluted matrigels. The media with or without $20 \mathrm{ng} / \mathrm{mL}$ BMP2 were placed below the cell permeable membrane. The cells invading to the bottom were stained with crystal violet and counted. Representative photos were shown. Scale bars, $100 \mu \mathrm{M}$. Average cell numbers of at least three fields were shown on the right. $\left({ }^{*} \mathrm{P}<0.05,{ }^{*} \mathrm{P}<0.01\right)(\mathrm{F})$ The vehicle or $20 \mathrm{ng} / \mathrm{mL}$ BMP2 pre-treated LLCs were injected into the hind leg muscles. To retain the BMP2 signaling activation in the hind leg muscles, $3 \mu \mathrm{g} / \mathrm{kg}$ vehicle or BMP2 were further injected into the hind leg muscles

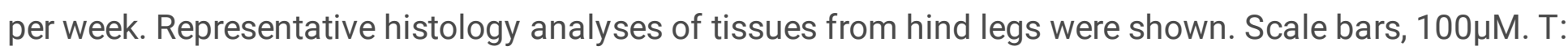
Tumor; B: Bone; M: Muscle. (G) Representative Smad1 immunohistochemical analyses of tissues from hind legs were shown. Scale bars of the $100 \times$ photos were $100 \mu \mathrm{M}$. T: Tumor; B: Bone; M: Muscle. $(\mathrm{H})$ Lysates of tissues from hind legs were indicated to immunoblotting. The band intensity of was normalized to $\beta$-Actin. The ratio of $p$-Smad1/5 and Smad1/5 bands intensity was analyzed. The experiments were repeated for three times and the average relative band intensity was shown. $\left({ }^{\star} P<0.05\right)$ 

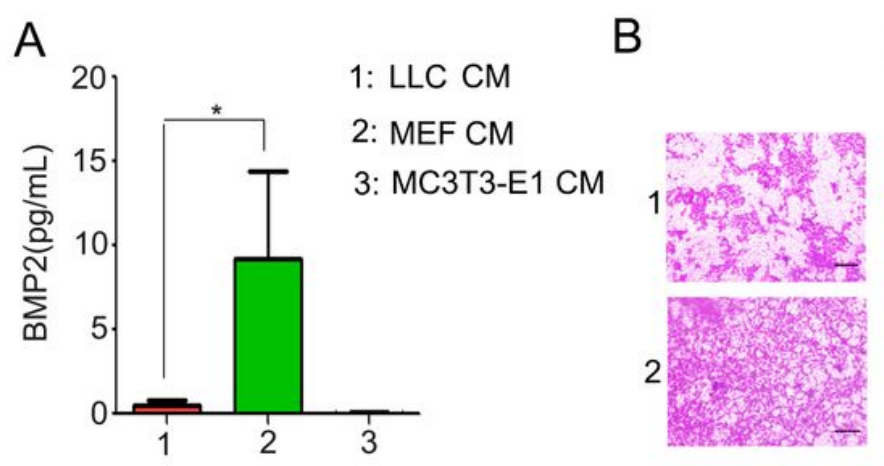

LLC

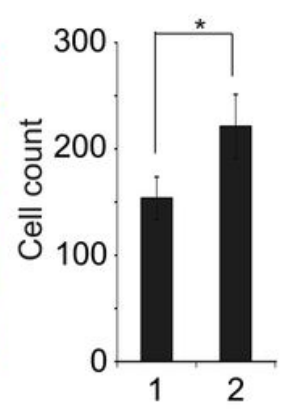

1:LLC 2: MEF

$\mathrm{E}$

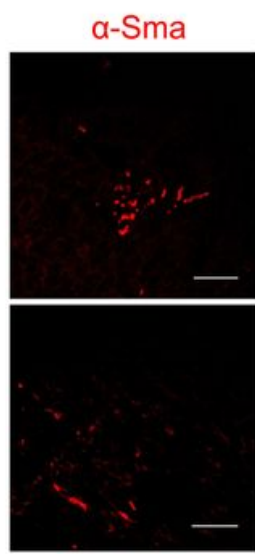

C

LLC

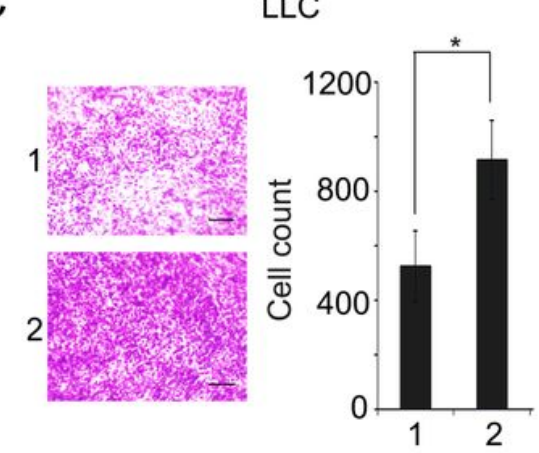

1: LLC CM 2: MEF CM

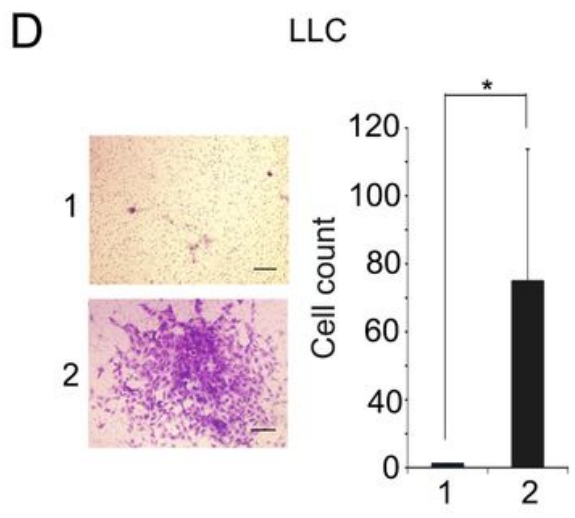

1: LLC CM 2: MEF CM

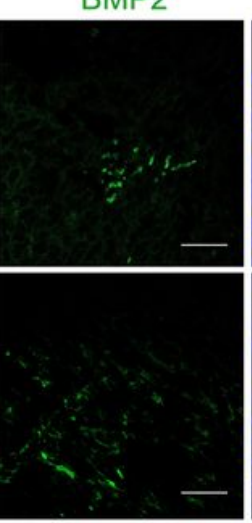

DAPI

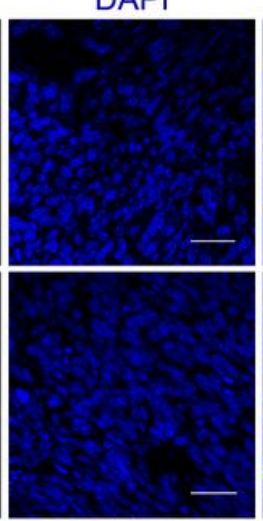

Merge

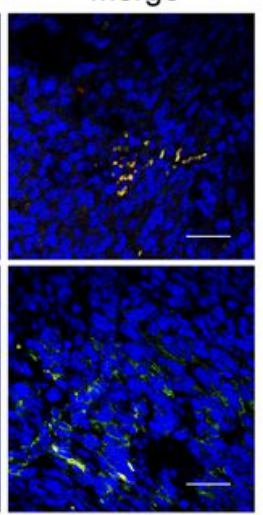

\section{Figure 5}

Stroma derived BMP2 enhanced migration and invasion of lung cancer cells. (A) $1 \times 104$ LLC, MEF or MC3T3-E1 cells were cultured with the same volume of DMEM with $10 \%$ FBS for three days. The concentration of BMP2 in the supernatant were measured by Elisa. (B) $1 \times 104$ LLCs in free culture media were placed on the upper layer of Corning cell culture insert with $8.0 \mu \mathrm{m}$ polycarbonate membrane. $1 \times 104$ LLC or MEF cells were placed below the cell permeable membrane with media with $10 \% \mathrm{FBS}$. The cells migrating to the bottom were stained with crystal violet and counted. Representative photos were shown. Scale bars, $100 \mu \mathrm{M}$. Average cell numbers of at least three fields were shown on the right. $\left({ }^{*} \mathrm{P}<0.05\right.$, $* * P<0.01$ ) (C) $1 \times 104$ LLCs in free culture media were placed on the upper layer of Corning cell culture insert with $8.0 \mu \mathrm{m}$ polycarbonate membrane. Media from 1×104 LLC or MEF cells were placed below the cell permeable membrane. The cells migrating to the bottom were stained with crystal violet and counted. Representative photos were shown. Scale bars, $100 \mu \mathrm{M}$. Average cell numbers of at least three fields were shown on the right. ( $\left.{ }^{\star} P<0.05,{ }^{*} P<0.01\right)$ (D) Corning cell culture insert with $8.0 \mu \mathrm{m}$ polycarbonate membrane were pre-treated with 10:1 DMEM and matrigels (BD BioSciences). 1×105 LLCs in free culture media were placed on the upper layer of the diluted matrigels. Media from 1×104 LLC or MEF cells were placed below the cell permeable membrane. The cells invading to the bottom were stained with crystal 
violet and counted. Representative photos were shown. Scale bars, $100 \mu \mathrm{M}$. Average cell numbers of at least three fields were shown on the right. $\left({ }^{*} \mathrm{P}<0.05,{ }^{*} \mathrm{P}<0.01\right)$ (E) Representative immunofluoresence

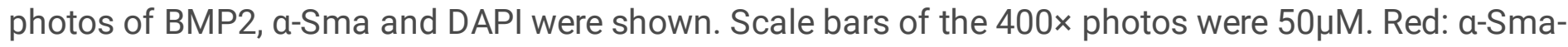
TRITC; Green: BMP2-FITC; Blue: DAPI.
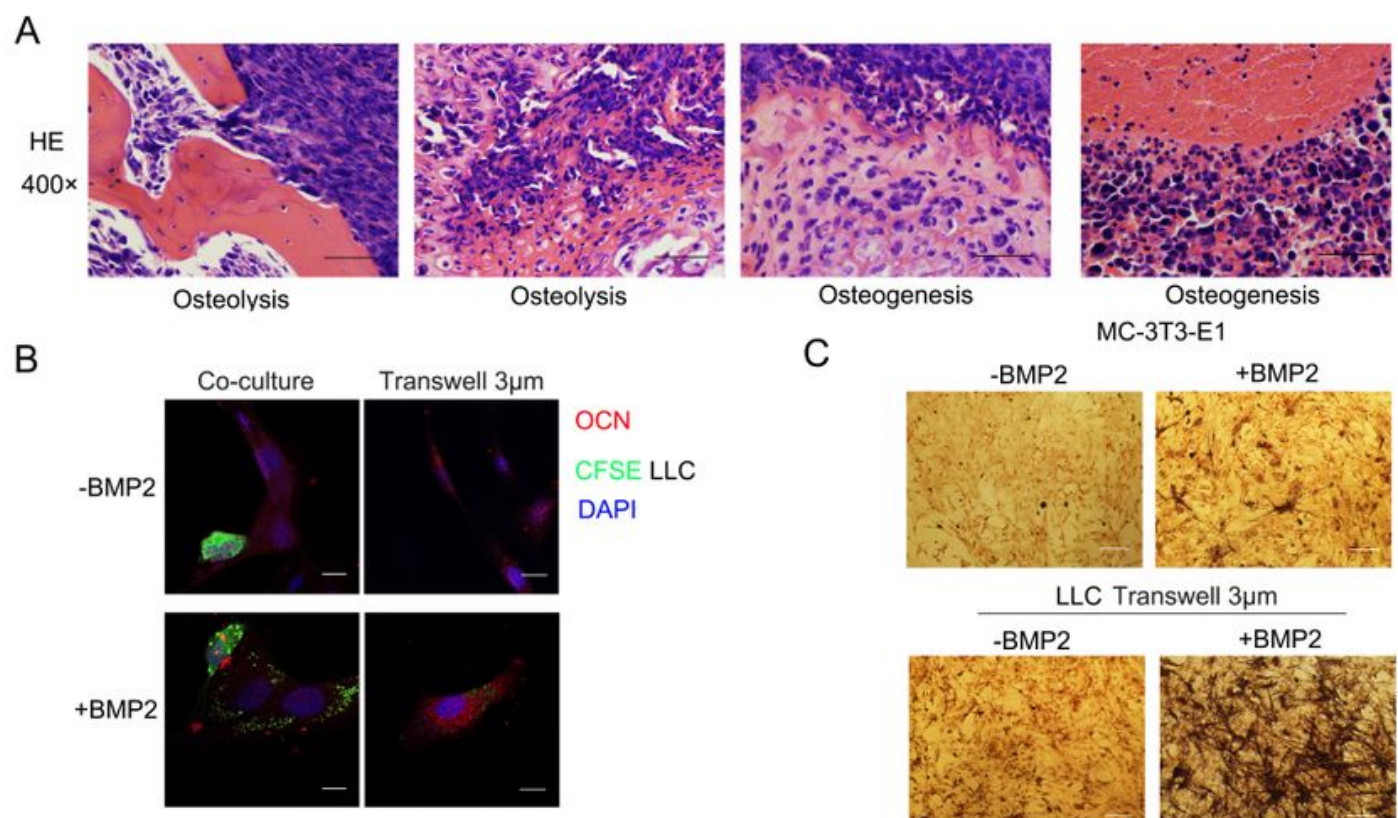

C MC-3T3-E1

D

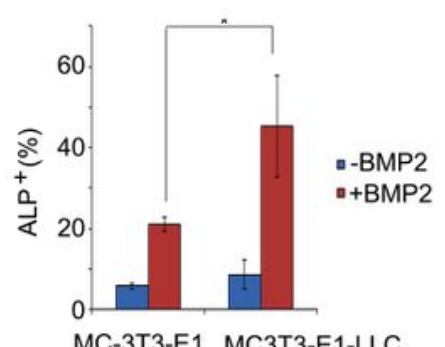

F

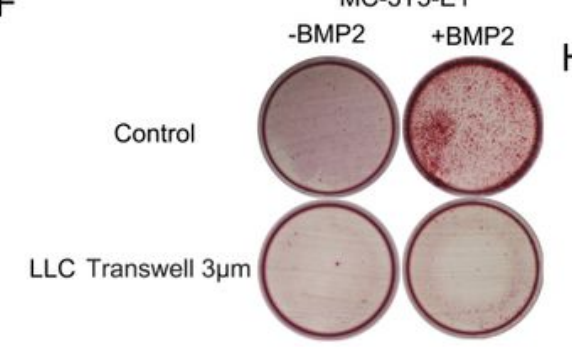

G

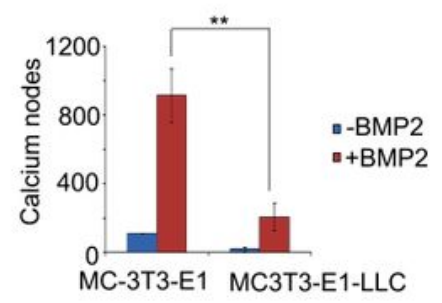

E
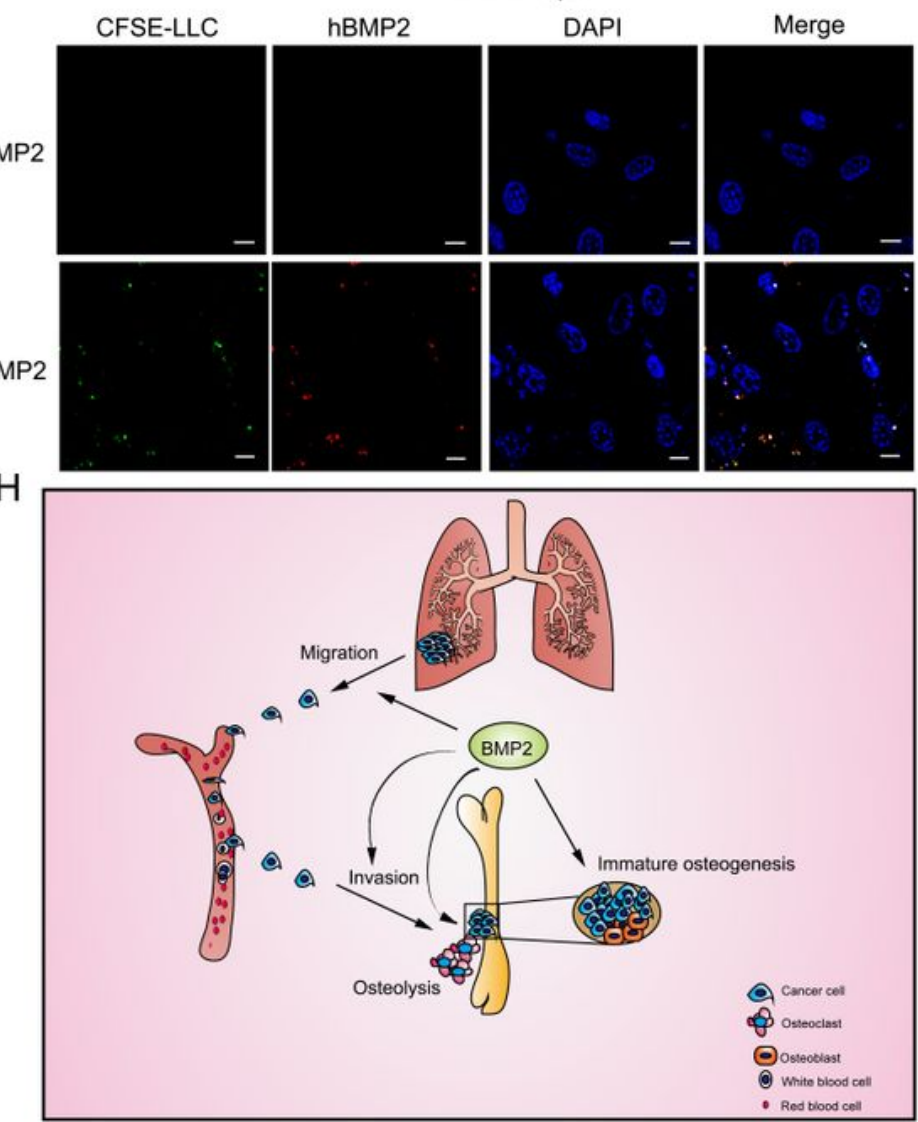

Figure 6 
BMP2 signaling enhanced immature osteogenesis in LLC bone metastasis tissues. (A) 1×106 LLCs were injected into tail veins of C57/BL6 mice, resulting in lung metastasis and bone metastasis.

Representative histology analyses of bone metastasis tissues from limbs or spines were shown. Scale bars, $50 \mu \mathrm{M}$. (B) $3 \times 104 \mathrm{MC} 3 \mathrm{~T} 3-\mathrm{E} 1$ cells were in the wells of 6 -well co-culture plates, and 3×104 CFSElabeled LLCs were in the Corning Cell Culture Inserts with $3 \mu \mathrm{m}$ polycarbonate membrane of the co-culture 6-well plates with $200 \mathrm{ng} / \mathrm{mL}$ BMP2 or vehicle. OCN were stained to show MC3T3-E1 cells. Representative immunofluoresence photos were shown. Scale bars, $100 \mu \mathrm{M}$. (C) LLCs or MC3T3-E1 cells were placed on

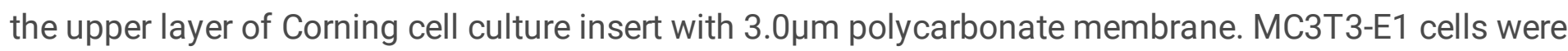
cultured below in media with or without $200 \mathrm{ng} / \mathrm{mL}$ BMP2 to be differentiated for seven days. ALP staining was conducted with BCIP/NBT Alkaline Phosphatase Color Development Kit. Representative photos were shown. Scale bars, $10 \mu \mathrm{M}$. (D) Average ALP+ cell numbers of at least three fields in (C) were shown on the right. ( $\left.{ }^{*} P<0.05,{ }^{*} P<0.01\right)$ (E) $3 \times 104$ MC3T3-E1 cells were seeded directly into the wells of the 6-well co-culture plates, and $3 \times 104$ CFSE-labeled LLC cells were seeded into the Corning Cell Culture Inserts with $3 \mu \mathrm{m}$ polycarbonate membrane of the co-culture 6-well plates with $200 \mathrm{ng} / \mathrm{mL}$ rhBMP2 or vehicle. rhBMP2 were stained (Red). Representative immunofluoresence photos were shown. Scale bars, $10 \mu \mathrm{M}$. (F) LLCs or MC3T3-E1 cells were placed on the upper layer of Corning cell culture insert with 3.0 $\mathrm{mm}$ polycarbonate membrane. MC3T3-E1 cells were cultured below in media with or without $200 \mathrm{ng} / \mathrm{mL}$ BMP2 to be differentiated for 14-21 days. MC3T3-E1 cells were stained with $1 \%$ Alizarin red $(\mathrm{pH}=8.3)$.

Representative photos were shown. (G) Average calcium node numbers in (F) of at least three wells were shown on the right. $\left({ }^{*} \mathrm{P}<0.05,{ }^{*} \mathrm{P}<0.01\right)(\mathrm{H})$ The working model of how BMP2 signaling enhanced bone metastases of NSCLC.

\section{Supplementary Files}

This is a list of supplementary files associated with this preprint. Click to download.

- Supplementary.docx 